NBER Working Paper Series

\title{
CALCULATING THE PRESENT VALUE OF AN ASSET'S \\ UNCERTAIN FUTURE CASH FLOWS
}

Stephen D. Nadauld

Brigham Young Un1versity

Work1ng Paper No. 268

\begin{abstract}
National Bureau of Economic Research, Inc. 204 Junipero Serra Boulevard, Stanford, CA 94305
\end{abstract}

July 1978

This paper has not undergone the review accorded official NBER publications; in particular, it has not been submitted for approval by the Board of Directors.

This research was supported by NSF-RANN Grant No. APR76-02511 through the National Bureau of Economic Research. 


\title{
CALCULATiNg THE PRESENT VALUE of AN ASSET'S UNCERTAIN FUTURE CASH FLOWS \\ Stephen D. Nadauld
}

\begin{abstract}
This paper describes both the theory and a computer program designed to calculate the present value of an asset's uncertain future cash flows. In this model expected flows may vary in each of " $t$ " future periods. Flows are adjusted to a certainty equivalent by a correction factor derived from a covariance matrix of the flows and market returns. The flows are discounted by a full specification of the term structure of the risk-free interest rate. The specific model illustrated in the paper is that of expected cash flows from a mortgage portfolio. The computer program calculates the expected cash flow, the uncertainty correction, and the term structure of interest rates. Algorlthms to solve for each of these factors are included. Alternatively, options are included to input the factors fr.m exogenous forecasts or projections. In addition to calculating the present values under each specification for the factors, the program compares the present values derived from each particular specification.
\end{abstract}

\author{
Stephen D. Nadauld \\ Department of Business Management \\ $395 \mathrm{JKB}$ \\ Brigham Young University \\ Provo, Utah 84602 \\ 801/374-1211, Extension 2220 or 4367
}




\section{INTRODUCTION}

This paper explains the application of a multiperiod uncertainty model whose theory has been discussed in previous articles. The model makes it possible to calculate the present value of uncertain future cash flows generated by any asset. The approach may be applied to a wide variety of asset classes. However, the paper uses as an example an actual computer program designed to calculate the present value of a mortgage portfolio and comments on how such a program could be modified and applied to other types of assets.

For the purpose of illustration, the approach is applied to mortgage portfolio data obtained from the Federal Home Loan Bank Board for 18 savings and loan associations in the San Francisco SMSA.

The usefulness of this approach to multiperiod valuation under uncertainty stems from its similarity to the common certainty formulation, which may be written as:

$$
\begin{aligned}
P V & =\frac{x_{1}}{(1+r)^{\top}}+\frac{x_{2}}{(1+r)^{2}}+\cdots+\frac{x_{T}}{(1+r)^{T}} \\
& =\sum_{t=1}^{T} \frac{x_{t}}{(1+r)^{t}}
\end{aligned}
$$

where:

$$
\begin{aligned}
& P V=\text { present vaiue of the income stream. } \\
& x_{t}=\text { certain cash flow received in period } t . \\
& r=\text { the risk free interest rate. }
\end{aligned}
$$


The equation (1) approach of discounting certain future cash flows by a rate which is the same for each period in the future should be familiar to the reader.

A similar simple closed form equation for discounting uncertain future cash flows is as follows:

$$
P V=\sum_{t=1}^{\infty} \frac{E\left(x_{t}\right)-\frac{\operatorname{cov}\left(x_{t},-R_{m t}^{-b}\right)}{E\left(R_{m t}^{-b}\right)}}{R_{F t}}
$$

where:

$$
\begin{aligned}
P V= & \text { present value of the income stream. } \\
x_{t}= & \text { the uncertain cash flow in period } t . \\
R_{i n t}= & \text { the future value of a dollar invested for } t \text { periods in } \\
& \text { the market portfolio. } \\
R_{F t}= & \text { the future value of a dollar invested for } t \text { periods in } \\
& \text { risk free bonds. } \\
b= & \text { level of proportional risk aversion which will be assumed } \\
& \text { equal to one. }
\end{aligned}
$$

Since the theoretical development behind this model has been discussed in previous papers, attention in this paper will be focused on application of equation (2).

In order to understand the application, it is important to note both the similarities and the differences of equations (1) and (2). The two formulations are similar in that both have cash inflows in the numerator, and both discount the cash flows for time value in the denominator. However, there are three important differences in the two equations. First, equation (2) uses expected cash inflows in the numerator $\left(E\left(X_{t}\right)\right)$ instead of the single point certainty cash flows of equation (1). Second, equation (2) has a term in the numerator which 
adjusts the expected cash flows for uncertainty. While this term appears complex, it may be thought of as simply a dollar amount which, when subtracted from the expected cash flows, supplies a certainty equivalent in place of the expected value. Third, the denominator in equation (2) employs a full specification of the term structure in place of the single level rate assumption of equation (1).

As suggested by the differences between equations (1) and (2), equation (2) is the conceptual basis for a much richer approach to the valuation of financial instruments. In addition to the obvious allowance for uncertainty, equation (2) allows for the cash flow in each period to be discounted by the risk free discount factor appropriate to that period and thus uses all the information available in the term structure. Also, the approach is extremely useful in dealing with the question of interest sensitivity since equation (2) makes a provision for specifying differences in the response of short and long rates and allows computation of the resulting impact on valuation.

Because the approach affords important insights into the impact of interest rate changes on valuation, it is important at the outset to specify how interest rate changes must be incorporated in the analysis. Interest rate changes have three separate effects. First, they may effect the expected future cash flows. In the mortgage application, for example, the impact of rate changes on future prepayments and defaults may alter considerably the expected cash flows. Second, a change in interest rates obviously changes the discount factors in the denominator. Third, and potentially the most troublesome, is the impact of interest rate change on the risk premium. The risk premium may be effected a) because of changes in aggregate risk tolerance, or b) 
through changes in the systematic riskiness of the asset that reflects a change in the joint distribution of asset cash flows and market returns.

To obtain maximum usefulness from the model, specific equations linking each of these three areas to interest rate change need to be incorporated into the analysis.

The process of applying equation (2) consists of four steps for any type of asset:

1. Determination of the expected cash flows for the asset.

This may be easy or more difficult depending on the nature of the instrument and the distribution of the cash flows. Mortgages, for example, require specification of future contract payments, future prepayments, and some estimate of defaults. In addition, time series or cross sectional data is necessary to give some insight into the distribution.

2. Specification of the risk free term structure.

There are several ways to determine the necessary term structures: a) present or past term structures may be calculated from risk free government securities, b) future term structures may be obtained from i) macro models such as the Penn-MIT model, ii) systematic adjustments of forward rates obtained from present term structures, iii) arbitrary specifications.

3. Calculation of the uncertainty adjustment term.

In order to calculate the uncertainty term, it is necessary to make assumptions which allow the computations to be done in the form 


$$
u_{t}=\operatorname{COR}\left(x_{t}, \frac{l}{r_{m}}\right) \operatorname{std}\left(\frac{l}{r_{m}}\right) \operatorname{std}\left(x_{t}\right) E\left(r_{m t}\right)
$$

where:

$$
\begin{aligned}
U_{t} & =\text { uncertainty adjustment for period } t . \\
C O R & =\text { coefficient of correlation. } \\
\text { Std } & =\text { standard deviation. } \\
E & =\text { expectation operator. } \\
r_{m} & =\text { the one period return on the market. }
\end{aligned}
$$

The correlation, standard deviations and expectation must be calculated from time series or cross sectional data obtained for asset cash flows and market returns.

4. Computation of the present value.

The respective elements of equation (2) are combined by the computer program into the calculated present value.

The remainder of the paper will be divided into two sections. Section I will explain the basic calculations in steps one through four and apply them to the question of valuing a mortgage portfolio, and Section II will demonstrate the computer program operations and give sample inputs and outputs.

\section{SECTION I}

\section{STEP 1: Determining the Expected Cash Flows}

The cash flows from a mortgage portfolio are made up of regular mortgage payments (including principal plus interest) and of mortgage prepayments. For the typical mortgage, the contract rate and maturity are fixed at the time of origination. The combination of rate and maturity specify a fixed paynent cash inflow that the mortgage promises 
to gererate at each point in the future. The payment is made up of principal plus interest and follows a prescribed amortization schedule depending on the rate and maturity. Because in the typical situation the promised individual mortgage payments are fixed, the promised portfolio cash inflow is fixed. Therefore, in general the value of the portfolio varies inversely with fluctuating market rates.

The difficulty that financial institutions have with fixed rate instruments is a well-known problem, and a recent attempt has been made by some mortgage-granting institutions to solve the problem by issuing variable rate mortgages. A variable rate mortgage allows the institution to raise (or lower) the mortgage contract rate according to the rise or fall of an index of appropriately constructed market rates. This kind of mortgage has some advantages to the institution, especially in times of rising interest rates. Variable rate mortgages have become popular with selected institutions and are being increasingly issued, especially by California institutions. However, the trend toward variable rate mortgages is relatively recent. Since the data gathered for this application are from portfolios formed in 1975 or before, they are made up almost wholly of fixed rate mortgages; and, for this reason, the analysis in the paper will concentrate on their behavior.

There are two factors that substantially complicate the cash inflows that are generated by a mortgage portfolio. The first of these is the prepayment option. Although the contract payments are spoken of as fixed, the mortgagee has the option to prepay part or all of the principal in conjunction with the refinancing or sale of the mortgaged property. Because of the mobility of many home owners, the option to prepay is often exercised, and the resulting prepayment cash flows are a 
substantial factor in analyzing the total cash flows from the mortgage portfolio. The second factor concerns mortgage defaults. The payments spoken of as fixed are only fixed in the sense that they are promises to pay. In the case of default, these promised payments are not realized by the mortgage granting institution.

\section{Fixed Payments}

The basic element of mortgage portfolio cash flows is derived from the fixed mortgage payment. The standard parameters of the fixed payment, self-amortizing mortgage, are straight forward. The regular monthly payment is determined as a function of the principle amount, contract rate, and term to maturity and may be computed by applying the following simple payment algorithm:

$$
\text { payment }=\frac{\text { Principle }}{1-\frac{1}{(1+r)^{t}}}
$$

where:

$$
\begin{aligned}
& r=\text { contract rate on monthly basis. } \\
& t=\text { term to maturity in months. }
\end{aligned}
$$

These fixed payment amounts must be adjusted in each period to take into effect foreclosures or prepayments which occurred in prior periods. The impact of the foreclosure or prepayment is to eliminate loans from the portfolio and therefore reduce the fixed payment portion of the cash flow.

\section{Prepayments}

Since mortgage holders have the option to pay down their mortgage by amounts in excess of the scheduled amortization, mortgage portfolios 
have cash flows which may in any period substantially exceed the prescribed fixed payments for the period. It is important to consider these prepayments, since their timing may greatly impact the value of the mortgage portfolio. There are several ways to include prepayments in the analysis. It is possible, for example, to use an arbitrary set of prepayment data in the form of annual mortgage termination rates. Termination rates are defined as a fraction of the portfolio balance that would be paid off in any year. The rates may be stated as a fraction of the original portfolio amount (fixed basis) or as a fraction of the remaining portfolio amount (current basis). Typical termination patterns are available from FHA data.

Another more interesting alternative is available for dealing with prepayments and illustrates the concept of linking cash flows to interest rate changes. The approach is based on a model developed by Curley and Guttentag (1972). The model explains mortgage termination rates as a function of policy year, maturity, the relationship between the current mortgage contract rate and original contract rate, and the discount points charged in the specified year. Their results are contained in a single equation of the following form: 1

\footnotetext{
'The numerator of the valuation equation requires expected cash flows. The prepayment cash flows are determined by finding the prepayment function (TR) which is the analog of the $\log _{T} \mathrm{TR}_{t}$ equation. It is clear that $E(x) \neq \exp [E(\ln (x))]$; but it can be shown that the difference is small. One approach is to suppose the generalized function $g(x)=$ $a+b x+c x^{2}+d x^{3}+\ldots$ Both $\ln (x)$ and $e^{x}$ meet this criterion. Expanding $g\left(x_{0}+\varepsilon\right)$ and taking the expectation $\left(E\left[g\left(x_{0}+\varepsilon\right)\right]\right)$ gives $x_{0}+E(\varepsilon)$ plus the expectation of higher order term of $\varepsilon^{2}$, i.e., $E\left[0(\varepsilon)^{2}\right]$. In the same fashion, $g[E(x)]=g\left[x_{0}+E(\varepsilon)\right]=x_{0}+E(\varepsilon)$ plus higher order terms of the square of the expectation, i.e., $O[E(\varepsilon)]^{2}$.
} 


$$
\begin{aligned}
\log T R_{t}= & -.56178+.90249 \log (P / M)-.10580\left(C_{t}-C\right)-.02179 D_{t} \\
& (-32.67)(56.29)
\end{aligned}
$$

where:

$$
\begin{aligned}
R^{2} & =.867 \\
T R_{t} & =\text { annual termination rate in year } t \text { (current basis) } \\
P & =\text { policy year } \\
M & =\text { maturity } \\
C_{t} & =\text { mortgage rate in year } t \\
D_{t} & =\text { discount in year } t \\
C & =\text { original contract rate }
\end{aligned}
$$

The termination rate in year $t\left(T R_{t}\right)$ is defined as a function of the portfolio balance that will be paid off in that year. The prepayment equation estimates current basis temination rates, but these may easily be converted to fixed basis rates if desired. The prepayment equation was estimated using FHA annual data covering the period 1951-67 for 20-, 25-, and 30-year mortgages. The absolute level of both longand short-term interest rates was generally lower during this period than during subsequent periods for which the equation may be applied. However, the variables in the prepayment equation which would be effected, namely the original contract rate and the mortgage rate in year $t$, enter the equation in the form of a yield differential. Since relative differentials or spreads have approximately the same range in subsequent periods as in the estimation period, the prepayment equation should retain its usefulness when applied to more recent data.

If $\varepsilon$ is small, $\varepsilon^{2}$ is very small, so $E\left[O(\varepsilon)^{2}\right] \cong 0$; and $E[\varepsilon]$ is small, so $O(E[\varepsilon])^{2}$ is also $\cong 0$. This leaves the constant and first order terms the same; and with only small differences in the second order terms, it appears safe to use the analog of the $\log T R_{t}$ equation in place of the expectation. 
The prepayment equation makes it possible to calculate prepayments and add them to the fixed mortgage payments for each period in the future. However, because the equation uses projected future mortgage rates, it is necessary to supply these rates in some fashion. This may be done arbitrarily or, since other numerator and denominator changes are driven by changes in short-term rates, it may be done by attempting to link future mortgage rates to future short-term interest rates.

As an illustration of an attempt to determine the nature of the relationship between mortgage rates and short-term rates, a monthly mortgage rate series from December of 1969 through December of 1975 was analyzed in conjunction with three month treasury bill rates over the same period. The most notable feature of these two series is the extremely high level of serial correlation that exists in each. For example, a regression of the spread between the mortgage rate and the treasury bill rate against the treasury bill rate yields the following equation:$$
\text { MRT }- \text { TBRT }=6.11-0.579 \text { TBRT }+\mathrm{e}
$$$$
\bar{R}^{2}=0.60 \quad(.34) \quad(.056) \quad \text { D.W. }=0.1398
$$$$
n=73
$$$$
\text { where } M R T=\text { mortgage } \text { rate, }
$$$$
\text { TBRT = treasury bill rate, }
$$$$
\text { D.W. = Durbin Watson statistic, }
$$$$
\text { and the figures in parentheses are standard errors. The }
$$
resulting t-statistics are significant at the $99 \%$ level.

The Durbin watson statistic of 0.1398 shows the high level of serial correlation in the residuals. This could be anticipated since the mechanism described by several practitioners for mortgage rate determination
} 
is to set the current period mortgage rate equal to the previous period's rate and adjust slightly upward or downward, depending on shortterm rate movements." The autocorrelation is strong enough to require second-order autocorrelation correction, which yields the following results:

$$
\begin{aligned}
\text { MRT - TBRT }=8.77-1.03 \text { TBRT }+1.65 \text { RHOI }-0.69 \text { RHO2 } \\
(.45)(.03) \quad(.085) \quad(0.087) \\
\text { D.W. }=1.83 \\
\bar{R}^{2}=0.98 \\
n=73
\end{aligned}
$$

The resulting t-statistics are again significant at the $99 \%$ level. However, there is a difficulty involved in using the above equation to predict future mortgage rates in the current setting. The prepayment algorithm requires a pattern of future mortgage rates over a thirty-year period in order to compute-a thirty-year pattern of prepayments and the resulting pattern of cash flows. When the equation is used to predict beyond five to ten periods, the predicted mortgage rates diverge rapidly from the average relationship that has existed in the past between mortgage rates and short-term treasury bill rates. This average spread was computed for 1961 through 1975 and was found to be approximately 210 basis points. Using the 210 basis point average spread to predict future mortgage rates was found to produce more reasonable prepayment patterns than those developed from the autocorrelation corrected equation. 


\section{Defaults}

While it is possible to relate the question of prepayments and interest rate changes in a fashion sympathetic to the overall approach, the problem of defaults is not so easily handled. The numerator related concern is essentially a question of how the expected value of cash flows are effected by defaults. Since it is reasonable to assume that short-term interest rates either directly or as a proxy may have some influence on default, it should be possible in principle to link rate changes through defaults to the expected cash flows. However, because default data were not available for the portfolios in the data sample, it was not possible to examine the linkage between rate changes and defaults. Nevertheless, the computer program written to do the calculation allows for the possibility of arbitrarily varying the default rates by year for each association. For example, the first year foreclosure rate could be determined as 2 percent, meaning that 2 percent of the book value of the portfolio would be eliminated for all subsequent periods. However, the program allows the user to specify an average percentage of the foreclosed amount to be recovered, and the recovered amount is added to the normal payment and prepayment cash flows for the period. The foreclosed mortgages are subtracted from the portfolio, and future cash flows from both regular payments and prepayments are appropriately reduced.

\section{STEP 2: Specification of the Risk Free Term Structure}

As suggested previously, there are several ways to obtain the necessary risk free interest rates that make up the denominator of equation (2). To examine the question of how changes in rates effect 
the resulting present values, it is useful to have both present and projected future term structures that can be used to discount the projected cash flows.

Current estimates of the term structure may be obtained from an estimation of the discount function accomplished by a computer program developed by J. Houston McCulloch [1975]. The basic concept is to fit a discount function to the observed prices of U.S. Government treasury obligations. The program uses as inputs the bid and ask prices of bill, note and bond quotes for a given date and applies an instrumental variables technique to fit the discount function to a cubic spline. (A flexible curve much like a polynominal.) An example of the program's output is the point yield for January 2, 1976, which appears in Table 1. These data are used directly as inputs to the present value calculation. The calculations are done in continuous time so that the denominator at any quarter $t$ is $\operatorname{DNOM}_{t}=\operatorname{EXP}\left(K_{t} \star t / 4\right)$ where $k_{t}$ is the point yield for period $t$ determined as in Table 1 .

The current term structure may be used as a basis for obtaining future term structures through a technique developed by Morrison [1977]. The technique employs a distributed lead to shift the whole term structure as a function of changes in short-term rates. Note that the impact of an interest rate change on a term structure with identical rates in each period, such as in equation (1), is to shift the term structure uniformly higher or lower. In other words, in such a case the response of both long- and short-term rates is assumed to be identical. However, by using the distributed lead, it is possible to capture in some measure the empirically observed differential response of short-and long-term rates to short-term rate changes. 
TABLE 1

"JAN. 2, 1976", "SHIFTED", AND "ARBItTARY" TERM STRUCTURES

Quarterly for Five Years

Shift Parameter Values: $R R=.015 \mathrm{RR}-\mathrm{HAT}=.015$

$I I=.0377$ II - HAT $=.1477$

\begin{tabular}{|c|c|c|c|}
\hline Month/Year & $\begin{array}{l}\text { Jan. 2, } 1976 \\
\text { Term Structure }\end{array}$ & $\begin{array}{c}\text { Shifted } \\
\text { Term Structure }\end{array}$ & $\begin{array}{c}\text { Arbitrary } \\
\text { Term Structure }\end{array}$ \\
\hline $3 / 76$ & 5.27 & 10.92 & 11.40 \\
\hline $6 / 76$ & 5.62 & 9.95 & 10.70 \\
\hline $9 / 76$ & 5.89 & 9.20 & 10.00 \\
\hline $12 / 76$ & 6.13 & 8.67 & 9.80 \\
\hline $3 / 77$ & 6.35 & 8.29 & 9.50 \\
\hline $6 / 77$ & 6.54 & 8.02 & 9.25 \\
\hline $9 / 77$ & 6.69 & 7.82 & 9.10 \\
\hline $12 / 77$ & 6.81 & 7.68 & 9.00 \\
\hline $3 / 78$ & 6.92 & 7.58 & 8.91 \\
\hline $6 / 78$ & 7.02 & 7.53 & 8.84 \\
\hline $9 / 78$ & 7.10 & 7.49 & 8.78 \\
\hline $12 / 78$ & 7.17 & 7.47 & 8.73 \\
\hline $3 / 79$ & 7.24 & 7.47 & 8.68 \\
\hline $6 / 79$ & 7.29 & 7.46 & 8.63 \\
\hline $9 / 79$ & 7.35 & 7.48 & 8.59 \\
\hline $12 / 79$ & 7.39 & 7.49 & 8.55 \\
\hline $3 / 80$ & 7.44 & 7.52 & 8.52 \\
\hline $6 / 80$ & 7.48 & 7.54 & 8.50 \\
\hline $9 / 80$ & 7.52 & 7.56 & 8.50 \\
\hline $12 / 80$ & 7.55 & 7.58 & 8.50 \\
\hline
\end{tabular}


The function used to shift the term structure takes the following form:

(3)

$$
\frac{\Delta r_{k}}{R_{F k}}=\frac{\Delta r r_{1}}{R_{F 1}} e^{-.41-.14 k}+\frac{\Delta i_{1}}{I_{1}} e^{-.14-.09 k}
$$

where:

$$
\begin{aligned}
r r_{1} & =\text { real one period rate. } \\
R_{F k} & =1+\text { the k-period risk free nominal compound rate. } \\
i_{1} & =\text { one-period inflationary expectation. } \\
I_{1} & ={ }^{++i_{1}} . \\
r_{1} & =r r_{1}+i_{1} . \\
\Delta & =\text { difference operator. } \\
k & =\text { time period in months. }
\end{aligned}
$$

As an example of how the function works, suppose:

$$
\begin{aligned}
r_{1} & =.06 \\
r r_{1} & =.03 \\
i_{1} & =.03 \\
\Delta r r_{1} & =.01 \\
\Delta i_{1} & =.03
\end{aligned}
$$

Since $\Delta r_{k}=r_{k}{ }^{*}-r_{k}$, it is possible to find a new value of the $k$ period rate from $r_{k}{ }^{*}=\left(1+r_{k}\right) \frac{.01}{1.06} e^{-.41-.14 k}+\frac{.03}{1.03} e^{-.41-.09 k}-r_{k}$. For $k+4$ and $r_{k}=.07$,

$$
\begin{aligned}
r_{k}^{*} & =(1.07) \frac{.01}{1.06} \mathrm{e}^{-.97}+\frac{.03}{1.03} \mathrm{e}^{-.77}+.07 \\
& =.0883
\end{aligned}
$$

Each period's rate making up the term structure may be shifted in the same manner. 
Table 1 contains an example of a shifted term structure which has been computed using equation (3) and the shift parameters shown in the table. As an alternative, it is possible to choose arbitrary term structures and employ them as the denominator of equation (2). An example of such an arbitrary designated term structure is also shown in Table 1. Figure 1 shows the shapes of the January 2, 1976, revised and arbitrary term structures. Each of these three term structures will subsequently be used to discount mortgage portfolio cash flows. of course, the method used for determining the term structure will restrict what may or may not be said concerning the resulting present values.

\section{STEP 3: Calculation of the Uncertainty Adjustment Term}

As will be recalled from equation (2), the uncertainty adjustment term takes the form:

$$
U=-\frac{\operatorname{cov}\left(x_{t},-R_{m t}^{-b}\right)}{E\left(R_{m t}^{-b}\right)}
$$

where:

$$
\begin{aligned}
& R_{m t}= \text { the one plus compound return on the market portfolio in } \\
& \text { period } t .
\end{aligned}
$$

In order to calculate a value for the term, it is necessary to make the following assumptions:

1. The level of proportional risk aversion (b) is set equal to one.

2. The returns on the maket portfolio are serially uncorrelated and the variance of market returns is constant. 
SHAPES OF THE JANUARY 2, 1976, "REVISED"

AND "ARBI IRARY" TERM STRUCTURES

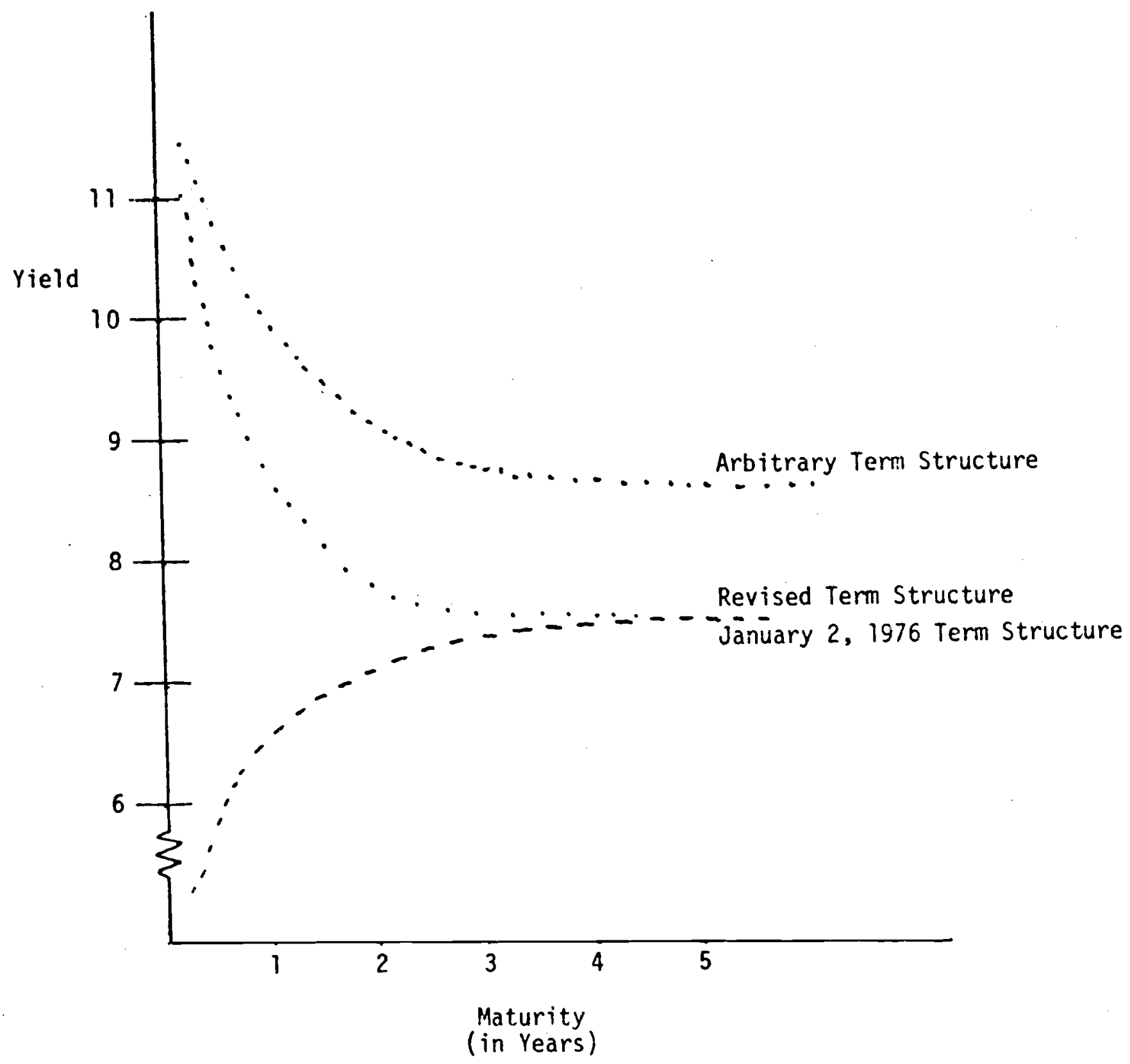


3. The cash flows are uncorrelated with previous period's market returns.

4. The correlation between current period cash flows and market returns is not a function of time or interest rates.

The above assumptions allow the covariance between the cash flow $\left(x_{t}\right)$ and the product of market returns $\left(R_{m t}\right)$ to be factored into the expectation of a product term and the covariance of a simpler term that can be calculated. Thus

$$
-\operatorname{cov}\left(x_{t},-R_{m t}^{-1}\right)=E\left(\frac{1}{R_{m t-1}}\right) \operatorname{cov}\left(x_{t}, \frac{1}{r_{m t}}\right) .
$$

The whole adjustment term becomes

$$
\begin{aligned}
\frac{-\operatorname{Cov}\left(x_{t},-R_{m t}^{-1}\right)}{E\left(R_{m t}^{-1}\right)} & =\frac{E\left(\frac{1}{R_{m t-1}}\right)}{E\left(\frac{1}{R_{m t}}\right)} \operatorname{cov}\left(x_{t}, \frac{1}{r_{m t}}\right) \\
& =\frac{\operatorname{cov}\left(x_{t}, \frac{1}{r_{m t}}\right)}{E\left(\frac{1}{r_{m t}}\right)} \\
& =E\left(r_{m t}\right) \operatorname{coR}\left(x_{t}, \frac{1}{r_{m t}}\right) \operatorname{std}\left(x_{t}\right) \operatorname{std}\left(\frac{1}{r_{m t}}\right)
\end{aligned}
$$

As suggested previously, the risk premium may be effected through either changes in aggregate risk tolerance or through changes in the joint distribution of mortage cash flows andmarket returns. Setting b - -1 is theoretically justified (see Hakansson [1971], Rubinstein [1973]), and in this context it essentially means that interest rate changes are assumed not to effect the risk premium through any impact on aggregate risk tolerance.

The second effect, namely the impact of interest rate change on the joint distribution of portfolio cash flows and market returns, can be seen quite clearly from equation (4). Equation (4) contains terms for 
the mean and standard deviation of the reciprocal of market returns, the standard deviation of cash flows, and the correlation between the cash flows and the reciprocal of market returns. Fortunately, it is possible to say something about how expected market returns vary with short-term interest rates as will be shown subsequently.

It is also possible that interest rate changes effect the correlation of cash flows with market returns and/or the standard deviation of cash flows. For example, in the case where investor expectations concerning interest rates impact on the distribution of cash flows through defaults, both the correlation and the standard deviation of cash flows would be effected. To measure the effect requires cross sectional data, including a number of observations of portfolio cash flows at each of several different interest rates. Because this data is not available, and since it is still useful to calculate the correlation coefficient, it is necessary to assume that the correlation is not a function of interest rates, and it can then be calculated from the available time series observations. For the same reason, the standard deviations of both the cash flows $\left(\operatorname{STD}\left[x_{t}\right]\right)$ and the reciprocal of market returns $\left(\operatorname{std}\left[\frac{1}{r_{m t}}\right]\right)$ are assumed to be invariant with respect to time and interest rates. It is useful to note that the data used to calculate both the correlations and standard deviations of cash flows is actual savings and loan mortgage portfolio data, which includes the impact of defaults, and therefore the correlations and standard deviation may be thought of as including average default characteristics.

Thus, under the stated assumptions, interest rate changes do impact on the risk premium, but only through an effect on the expected market return. It is difficult to estimate the size or nature of the bias that 
may be introduced by the above assumptions. When risk premia are stated in terms of yield differentials, the suspicion is that they exhibit sizable changes. For example, the yield spread between long-term government bonds and mortgage rates ranged from 145 to 375 basis points over the time period of study. However, it is important to note that a "yield" calculation assumes that interest rates are level through time and that contract rates or coupon rates represent certain cash flows. Therefore, any adjustments in expected cash flows, in the term structure or in strict risk premium changes, are thrown together into the reported "yield". Since the above analysis does incorporate interest rate changes into the term structure, the expected cash flows and the risk premium, it is difficult to estimate how much of the difference in observed yield spreads may be unaccounted for.

To incorporate the uncertainty adjustment term in the analysis, values for each of the four terms of equation (4) must be estimated. Consider first the term $E\left(r_{m t}\right)$ which is the expected one plus return on the market portfolio. In this application the return is assumed to be a function of the level of risk-free interest rates. Since the uncertainty adjustment is done on a quarterly basis the appropriate relationship is between the quarterly return on the market and the three-month treasury bill yield. This relationship was estimated for the 25 quarters from 1969 IV to 1975 IV. Table 2 gives the results: 


\section{TABLE 2}

EXCESS MARKET RETURN $\left(r_{x}\right)$

VERSUS THE RISK-FREE RATE $\left(r_{t}\right)$

$$
\begin{array}{rlrl}
r_{x}=.140-3.19 r_{t} & \text { Durbin Watson } & =1.83 \\
(1.99)(2.79) & \text { Standard Error } & =.084 \\
N & =25
\end{array}
$$

Figures in parenthesis are t- statistics.

Since $r_{x}=r_{m}-r_{t}$, the return on the market portfolio in any period can be determined from the risk-free rate for the period in the form:

$$
\hat{r}_{m t}=.14-2.19 \hat{r}_{f t}
$$

One way of obtaining a series of future three month spot rates needed as the independent variable is to obtain from the term structure the liquidity adjusted three month forward rates. (Assuming that the liquidity adjusted three month forward rates are unbiased projection of future three month spot rates.) These forward rates can be computed from the term structure by using the relationship

$$
e^{\left(r_{t}\right)(1 / 4)} e^{\left(k_{t}\right)(1 / 4)}=e^{\left(k_{t}+1\right) \frac{(t+1)}{4}}
$$

which, when solved for $r_{t}$, gives

$$
r_{t}=4 \ln \frac{e^{\left(k_{t}+1\right)}\left(\frac{t+1}{4}\right)}{e^{\left(k_{t}\right)(t / 4)}}
$$

where:

$$
\begin{aligned}
& r_{t}=\text { rate on three month loan to begin at time } t . \\
& k_{t}=\text { point yield on a risk-free security of maturity } t .
\end{aligned}
$$


TABLE 3

ESTIMATES OF MEAN LIQUIDITY PREMIUM $p\left(m_{1}, m_{2}\right)^{1}$

(Standard errors in parentheses)

\begin{tabular}{cccc}
\hline $\mathrm{m}_{1}$ & $\mathrm{~m}_{2}=3$ months & $\mathrm{m}_{1}$ & $\mathrm{~m}_{2}=3$ months \\
1 month & $0.09(0.01)$ & 2 years & $0.22(0.06)$ \\
2 months & $0.14(0.02)$ & 3 years & $0.22(0.06)$ \\
3 months & $0.17(0.03)$ & 5 years & $0.22(0.06)$ \\
6 months & $0.21(0.05)$ & 10 years & $0.22(0.06)$ \\
9 months & $0.22(0.06)$ & 20 years & $0.22(0.06)$ \\
1 year & $0.22(0.06)$ & 30 years & $0.22(0.06)$ \\
\hline
\end{tabular}

Source:. "An Estimate of the Liquidity Premium" J. Houston McCulloch. Dissertation submitted to Department of Economics, University of Chicago, Chicago, Illinois, June 1973, page 57. ${ }^{1}$ Table 3 gives the premium on an $m_{2}$ maturity loan entered into $m_{1}$
years into the future. 
Before the calculated forward rate $\left(r_{t}\right)$ can be used as a spot rate projection, it must be adjusted by subtracting off a liquidity premium the three-month liquidity premia estimated by McCulloch [1975] are shown in Table 3.

Calculation of the correlation coefficient, $\operatorname{COR}\left(x, \frac{1}{r_{m}}\right)$ requires cash flow data from the mortgage portfolio ard a corresponding series of market returns. For this application, the data employed were six years of quarterly cash flows from a savings and loan association mortgage portfolio and market return data for the same period from the CRSP tapes. Since the mortgage portfolio cash flows were separated into interest and principle payments, three separate correlation coefficients were calculated. $\rho_{1}$ is the correlation between the interest payments and the reciprocal of market returns, $\rho_{2}$ is the correlation between principle payments and the reciprocal of market returns and $\rho_{3}$ is the correlation between the combined cash flows and the reciprocal of market returns. Table 4 shows the results of the calculations for a typical savings association's mortgage portfolio.

TABLE 4

CORRELATIONS BETWEEN THE RECIPROCAL OF MARKET RETURNS AND MORTGAGE PORTFOLIO CASH FLOWS

\begin{tabular}{lcc}
\hline$\rho_{1}$ & $\rho_{2}$ & $\rho_{3}$ \\
\hline-.22 & .52 & .45 \\
correlation coefficients greater than 0.36 are significant at the 90 \\
percent level for $\frac{\rho^{2}}{k-1} \cdot \frac{n-k}{1-\rho^{2}} \sim F(1,20)$.
\end{tabular}


When examining the results, it should be noted that the sign of the uncertainty adjustment term in equation (4) is positive. This may seem counter-intuitive, since the usual notion is to subtract from the expected cash flow a term that reflects the undesirability of highly correlated cash flows. However, because the correlation calculated here is between a cash flow and the reciprocal of the market return, the signs will be opposite those nomilly expected. Since the sign of the correlation may be either positive or negative, the sign of the whole adjustment term may be either positive or negative. Thus, the sign of the correlation coefficient determines whether the mortgage portfolio's value is increased or decreased when held in a portfolio with other assets. For the above example, the combined cash flows have a positive correlation with the reciprocal of market returns (meaning the correlation betweem cash flows and regular market returns would be negative) and, therefore, the value of the mortgages is increased when held in conjunction with the market portfolio.

To complete the risk adjustment term, it is necessary to calculate the standard deviation of both the reciprocal of market returns and of the portfolio cash flows. From the CRSP data, the standard deviation of the reciprocal of the one-plus market return was computed to be 0.0882 for the sample time period. For the portfolio cash flows, the quarterly standard deviation was calculated to be 1,708 dollars.

It should be noted that for cash flows that are serially uncorrelated and have a growth rate with a stationary mean, the standard deviation can be computed as:

$$
\operatorname{std}\left(x_{t}\right)=x_{0}\left[\left(\sigma_{g}^{2}+\mu_{y}^{2}\right)^{t}\right]^{1 / 2}
$$


where $\quad x_{t}=$ cash flow at time $t$

$g=1+$ rate of growth of cash flows

$\sigma=$ standard deviation of the growth rate

$\mu=$ mean of the growth rate

However, the cash flows from a mortgage portfolio do not fit this pattern because they do not grow over time. Since regular payments are fixed, any variation in the cash flows results from variation in the prepayment or foreclosure rates. It is generally assumed that as a portfolio ages, the absolute number of foreclosures and prepayments decrease. Consequently, the standard deviation of cash flows ought to also decrease with time. However, because analysis of how the standard deviation of cash flows behaves as a function of foreclosure rates, prepayments, and time was not possible, the program assumes for this application that the standard deviation is constant over time.

\section{Step 4: Calculation of the Present Value}

Calculation of the present value requires that each of the previously described steps be combined in the appropriate relationship according to equation (2). The computer program developed to do the calculations performs essentially five operations; four operations are related to the numerator and one to the denominator. These operations are discussed relative to the mortgage portfolio application and may need to be altered slightly for use in other contexts. They are essentially a review of steps one through three.

With respect to the numerator, the program first takes the individual mortgage data for each mortgage in the portfolio and calculates the future fixed monthly payments. Second, it calculates a series of future 
mortgage rates based on a specified term structure and uses them in conjunction with the prepayment algorithm to calculate the dollar amount of prepayments in each period. The program then applies an arbitrarily deternined set of foreclosure rates to the portfolio. The foreclosure rates can be varied at will but are not included as a function of any other endogeneous or exogeneous parameters. At this point, the program combines the fixed payments, prepayments and foreclosures for each loan into a specified quarterly cash flow for the entire portfolio. As a fourth step, the parameters of the uncertainty adjustment term are computed and added to or subtracted from the expected cash flow for each period.

The denominator calculation consists of taking the series of forward rates describing the term structure and forming the appropriate discount factor for each period. The discounted, uncertainty adjusted cash flows are summed over the total number of periods, and the sum is the resulting present value.

Tables 5 and 6 show the results of applying the approach to 18 San Francisco SMSA savings and loan association portfolios. The results in Table 5 have been calculated assuming uncertainty, no foreclosures and the term structure and revision discussed in Step 2. Note that the portfolio values as of January 2,1976 , exceeded the book values in every case. This is because the rates represented by the January 2, 1976, term structure were lower than the average mortgage portfolio contract rates. Note also that even when the portfolio cash flows were valued using the revised downward sloping term structure, the present values remained above book value. This occurred because the portfolio cash flows are received over a very long period of time; and, even 
0

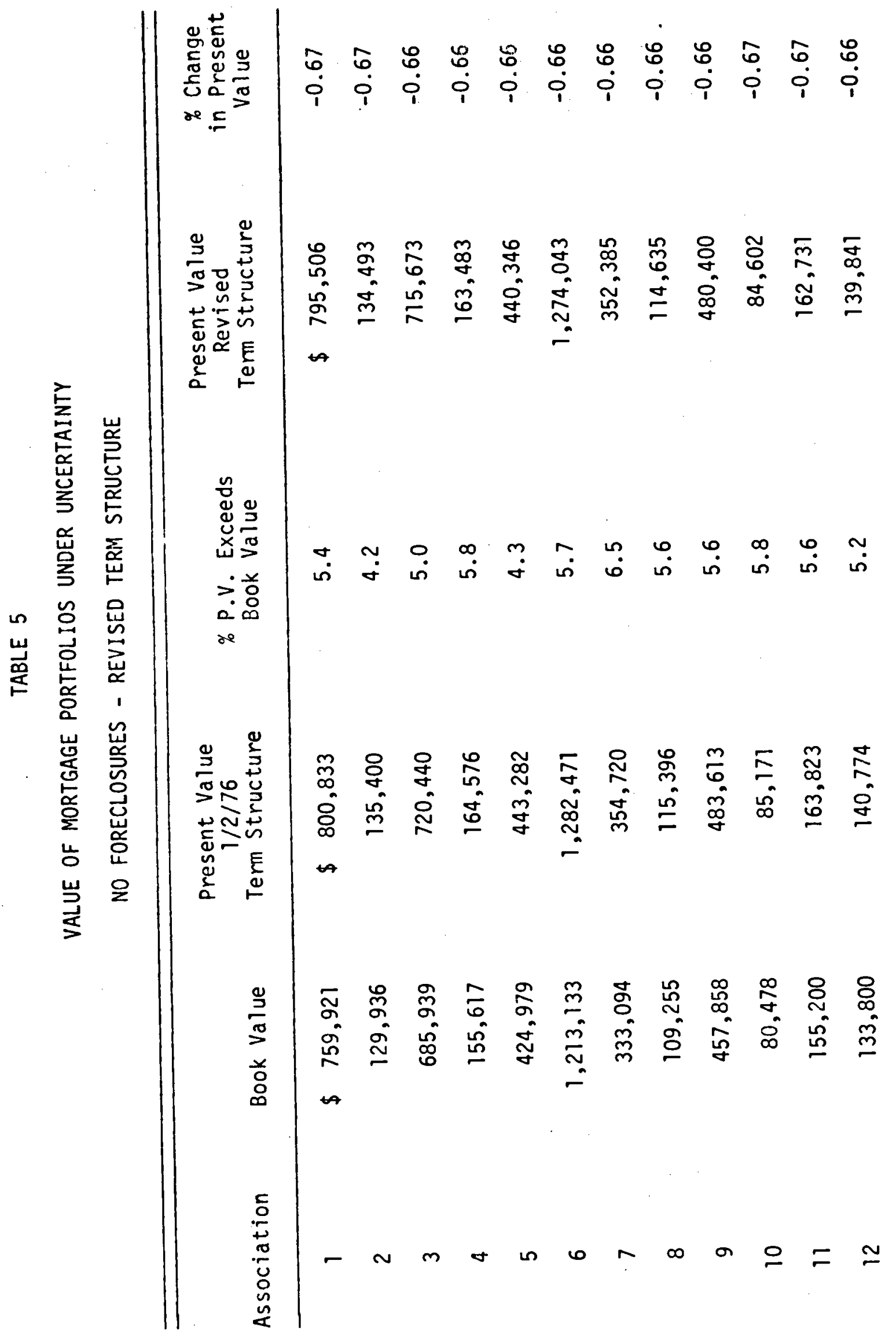




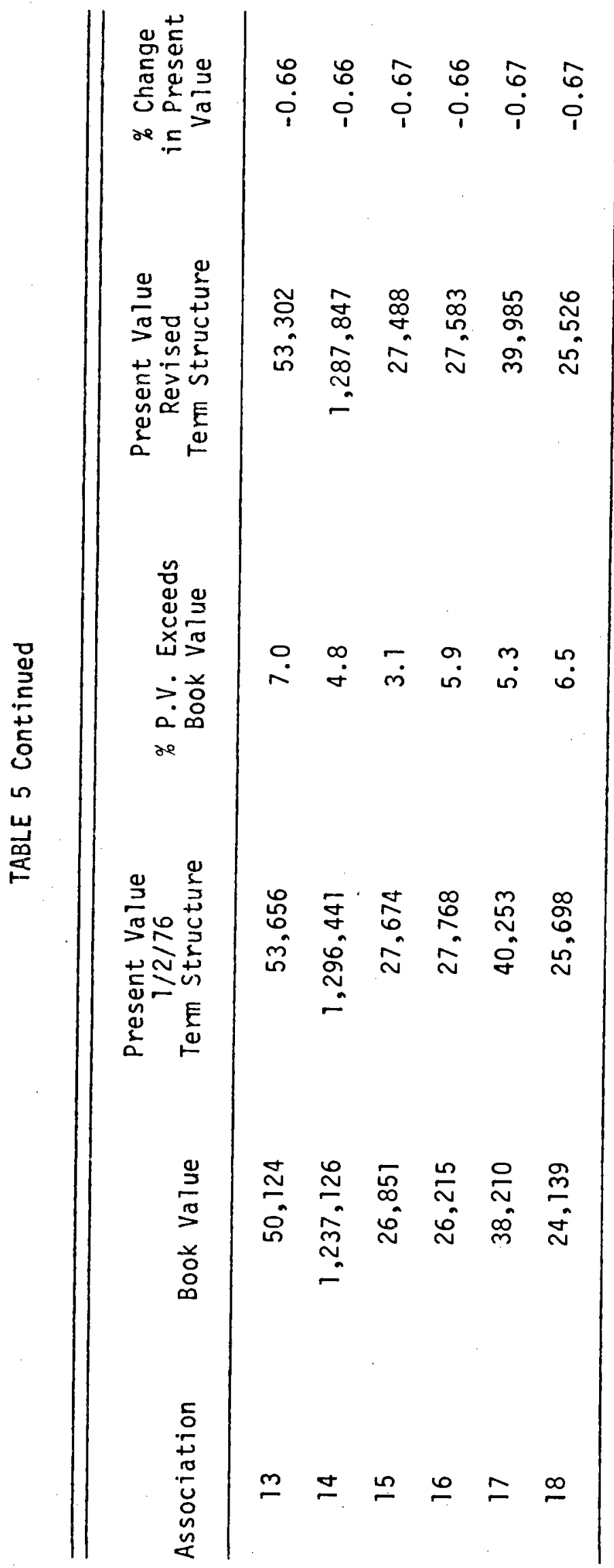


though the term structure was shifted upward, the nature of the shift was such as to leave long term rates relatively unchanged.

Table 6 shows the impact of discounting the expected mortgage cash flows by the arbitrarily designated term structure described previously. As seen most clearly from Figure 1 , the main difference between the revised and arbitrary term structures is that the arbitrary tem structure exhibits higher long term rates. Discounting by this term structure decreases the mortgage portfolio values by more than 6 percent in every case.

\section{SECTION II}

\section{PROGRAM OPERATION AND SAMPLE INPUTS AND OUTPUTS}

This section contains more specific information and description concerning the computer program discussed previously. The first part of the section describes the real time program requests and the nature of the inputs requested. The second part contains a sample of the program output. A listing of the program and sample input data files are contained in Appendices $A$ and $B$ respectively.

The program is currently set to run on a Dec 10 computer system; however, only slight modifications of certain control statements would be required to make it compatible with other similar time shared systems. The input steps correspond with the previous discussion on projecting cash flows, adjusting for uncertainty, etc. Table 7 contains a sample of the program statements and inputs and should be referred to in conjunction with the description of program steps.

After logging in and receiving the prompt character, the user types RUN FLO, and the computer responds with the first input requested. 
TABLE 6

VAL.UE OF MORTGAGE PORTFOLIOS UNDER UNCERTAINTY

NO FORECLOSURES - ARBITRARY TERM STRUCTURE

\begin{tabular}{|c|c|c|c|c|}
\hline Association & Book Value & $\begin{array}{c}\text { Present Value } \\
1 / 2 / 76 \\
\text { Term Structure }\end{array}$ & $\begin{array}{l}\text { Present Value } \\
\text { Arbitrary } \\
\text { Term Structure }\end{array}$ & $\begin{array}{l}\text { \% Change } \\
\text { In Present } \\
\text { Value }\end{array}$ \\
\hline 1 & 759,921 & $\$ 800,833$ & $\$ 749,391$ & -6.42 \\
\hline 2 & 129,936 & 135,400 & 126,777 & -6.37 \\
\hline 3 & 685,939 & 720,440 & 673,916 & -6.46 \\
\hline 4 & 155,617 & 164,576 & 154,015 & -6.42 \\
\hline 5 & 424,979 & 443,282 & 414,687 & -6.45 \\
\hline 6 & $1,213,133$ & $1,282,471$ & $1,199,008$ & -6.51 \\
\hline 7 & 333,094 & 354,700 & 331,642 & -6.51 \\
\hline 8 & 109,255 & 115,396 & 107,923 & -6.48 \\
\hline 9 & 457,858 & 483,613 & 452,558 & -6.42 \\
\hline 10 & 80,478 & 85,171 & 79,738 & -6.38 \\
\hline 11 & 155,200 & 163,823 & 153,388 & -6.37 \\
\hline 12 & 133,800 & 140,774 & 131,672 & -6.47 \\
\hline 13 & 50,124 & 53,656 & 50,178 & -6.48 \\
\hline 14 & $1,237,136$ & $1,296,441$ & $1,213,063$ & -6.43 \\
\hline 15 & 26,851 & 27,674 & 25,917 & -6.35 \\
\hline 16 & 26,215 & 27,768 & 25,986 & -6.42 \\
\hline 17 & 38,209 & 40,253 & 37,685 & -6.38 \\
\hline 18 & 24,139 & 25,698 & 24,060 & -6.37 \\
\hline
\end{tabular}


- RuRi Fln

ENTER THE SAVINGS \& LCIAN DUCKET JO. AiNU THE \# uF loANS 2,6

WHEN OU YOU WANT THE CASH FLJUS TU STARI PRINTING?

76

IS THE LOAN DATA DIN DISK?

WHAT FILE IS IT IN?

LOAN.AC

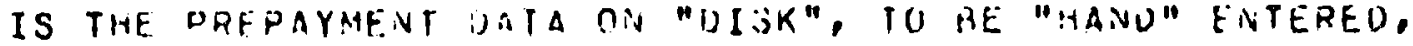
c OR TU HE "CALCULGIED"?

DO YOLI: AR:T IT CALCLLATEO FHIJM "ARBITRAKY" HURTGAGE RATES,

OR THF "TERM" SIIMCIURE UETFHMINEO MUSTGAGE. RATES?

T

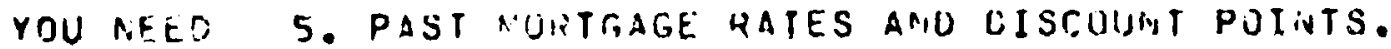
WHAT FILE ARE THEY LIV?

MORT,PST

NHAT FILE ARE THE LIXUIOITY PREMIUMS IN?

L.OT

WHAT SPREAJ DO YOU PRUJECT FUR THE PUKTGAGE RATE OVER THE TRECBISY BILL RAIE? (I.E. O.021)

.021

WHERE AKE THE EXPECTEU FIRECLUIURE RAIES FOUNU?

FDRC.RAT

NHAT PEHCENT OF FOABLLOS:JEES DU YOU EXPECT TO RECOVER? 100

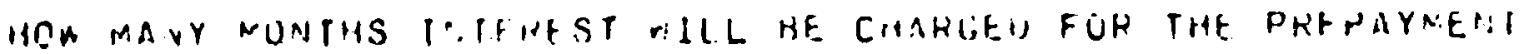

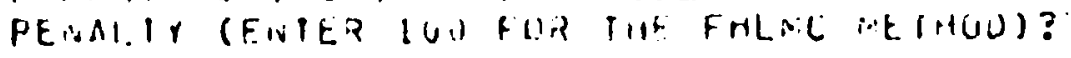

u

WHERE A.A THE $K \cdot i$ rHIIIC?

$K . O T$ 
NO YUU WANT TO ARHITRAKILY SHIFT THE IERIA STRUCTUHE?

ENTER RI, RR-HAT, II, ANU IIOHAT

$.015, .015, .0377, .1477$

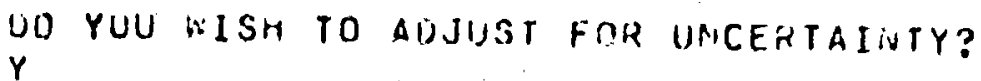

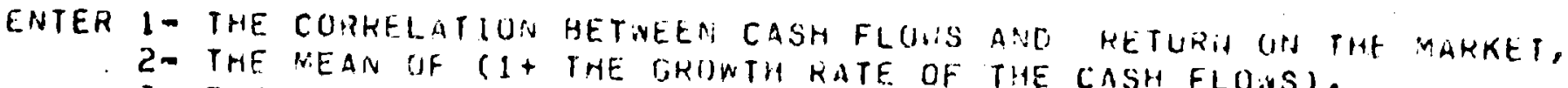
2- THE MEAN UF (I+ TME GROWTH RATE OF THE CASH FLOUS). $.5,0,2000$

JO YOU WANT THE MONTHLY CASH FLOWS PHIMTED DUT?

$*$

DD YOU IRANT DETAILEN PKFPAYMENTS, EIC.?

.

STOP

ESL OF EXECUTION

CFU TIME: 1.06 ELAPSFL TINE: $1: 26.45$

EXI1 


\section{Projecting Cash Flows}

Itens 1-12 allow for the calculation of cash flows for a savings and loan mortgage portfolio. These items could be modified to accept coupon bond data or any other data representing cash flows from financial instruments.

1. ENTER THE SAVINGS \& LOAN DOCKET NO. AND THE NUMBER OF LOANS.

The user must input two numbers separated by a comma. The first number is simply a number that identifies the run. This number will appear in the heading of the output. The second number indicates how many separate loans will be entered for analysis. After the second number, the user enters a carriage return which tells the computer to go to the next step.

2. WHEN DO YOU WANT THE CASH FLOWS TO START PRINTING?

User enters a two digit number (i.e., 76) that specifies the first year the output will begin to appear.

3. IS THE LOAN DATA ON DISK?

If the user inputs "Y" meaning yes, the computer responds with statement 4 . If the user inputs "N", the computer responds with statement $3 A$.

3A. WHAT WOULD YOU LIKE TO CALL THE FILE?

The user inputs a file name to which the loan data will be assigned.

3B. ENTER 1 - THE YEAR LOAN HAD THAT AMOUNT

2 - THE YEAR LOAN HAD THAT AMOUNT

3 - THE CONTRACT RATE 
4 - THE NUMBER OF MONTHS LEFT TO MATURITY

5 - THE AGE (IN MONTHS) OF LOAN

see Appendix $B$ and file LOAN.A2 for an example of data input.

4. WHAT FILE IS IT IN?

The response to this statement must be the name of a data file in which the loan data has previously been put. Loan data must include for each loan the four items described in 3B. A typical file for 6 loans would appear as shown in file LOAN.A2 (Appendix B).

5. IS THE PREPAYMENT DATA ON "DISK" TO BE "HAND" ENTERED OR TO BE "CALCULATED"?

The user may respond with "D", "H", or "C".

A " $D$ " response means that the user has previously placed in a disk file the fraction of mortgages in the specified year that will be terminated. A typical data file would contain thirty decimal fractions similar to those that appear on the output for each loan under "has the following prepayment experience". An "H" response means the user is prepared to input the decimal fractions at the terminal one at a time separated by commas .

A " $C$ " response means the user wishes the computer to calculate the prepayment fractions based on the algorithm described in the text. The calculated fractions are printed out for each loan on the output. A "C" response invokes statement 6.

6. DO YOU WANT IT CALCULATED FROM "ARBI TRARY MORTGAGE RATES" OR THE TERM STRUCTURE DETERMINED MORTGAGE RATES?

The user may respond with an "A" or a "T". The "A" response means the user wants to specify a set of future annual mort- 
gage rates which will be used in the prepayment algorithm to calculate the prepayment fractions. This allows the user to uncouple the prepayment fractions from the term structure and have them calculated from arbitrarily determined future mortgage rates. After an "A" response, the computer will come back and ask for the file name in which the future mortgage rates have been stored.

The " $T$ " response instructs the computer to calculate the forward rates from the term structure and use the forward rates to calculate the future mortgage rates that are to be used to determine the prepayment fractions.

7. YOU NEED $X$ PAST MORTGAGE RATES AND DISCOUNT POINTS, WHAT FILE ARE THEY IN?

The program has been written so that prepayment fractions would be applied to loans which were closed in previous years. In order to calculate the prepayment experience, the computer uses the prepayment algorithm and requires as inputs the past mortgage rates and discount points. These need to be placed in a data file. See file MORT PST.

8. WHERE ARE THE LIQUIDITY PREMIUMS?

The user responds with the file name. The file may specify the McCollough liquidity premium or any arbitrarily chosen set. See file L.DT.

9. WHAT SPREAD DO YOU PROJECT FOR THE MORTGAGE RATE OVER THE TREASURY BILL RATE? (I.E. 0.021)

The user inputs a decimal fraction. For example, the .021 adds 2.1 percent to an 8.0 percent forward rate to give a 10.1 percent mortgage rate. 
10. WHERE ARE THE EXPECTED FORECLOSURE RATES FOUND?

The user inputs a file name. See, for example, FORC.RAT.

11. WHAT PERCENT OF FORECLOSURES DO YOU EXPECT TO RECOVER?

The user inputs a number such as 50 (50 percent) or $100(100$ percent), which specifies the percent of the value of foreclosed property that will be realized.

12. HOW MANY MONTHS INTEREST WILL BE CHARGED FOR THE PREPAYMENT PENALTY (ENTER 100 FOR THE FHLMC METHOD)?

User enters a number like 6 (6 months) or 0 (no months interest penalty).

\section{Specification of the Risk Free Term Structure}

Items 13-15 relate to the development of discount factors which make up the denominator of equation (2).

13. WHERE ARE THE K'S FOUND?

User enters a file name. See for example K.DT. The K's are the quarterly rates (on annual basis) obtained from the McCollough program that specify the term structure.

14. DO YOU WANT TO ARBITRARILY SHIFT THE TERM STRUCTURE?

User responds with " $Y$ " or "N". A "Y" response means the user does not wish to have the term structure shifted by using the compulational algorithm but prefers to arbitrarily designate a new shifted term structure. The computer requests the file name of the shifted term structure. See for example file AK.DT.

A " $N$ " response means the user wishes to use the algorithm for shifting the term structure, and the computer responds with statement 15. 
15. ENTER RR, RR-HAT, II, AND II-HAT

The user enters four decimals separated by commas. RR and II are respectively the real rate and rate of inflation components that make up the nominal short term ( 3 month) rate. RRHAT and II-HAT are the real and inflationary rate components that are projected to make up the short term nominal rate in the shifted term structure.

The Uncertainty Adjustment Term

Items 16 and 17 allow for the computation of the uncertainty adjustment term as previously described.

16. DO YOU WISH TO ADJUST FOR UNCERTAINTY?

User enters "Y" or " $N$ ". An " $N$ " response sets the uncertainty adjustment term to zero. If the user responds in the affirmative, the computer proceeds to statement 17.

17. ENTER 1 - THE CORRELATION BETWEEN CASH FLOWS AND RETURN ON THE MARKET.

2 - THE MEAN OF ( 1 + THE GROWTH RATE OF THE CASH FLOWS).

3 - THE STANDARD DEVIATION.

Two separate versions of the uncertainty adjustment term are available in the program. Both use the correlation coefficient, which is entered as the first input. The first version for uncertainty adjustment uses the mean arid standard deviation of the $1+$ growth rates of cash flows. These data would be entered, for example, as $\mu=1.05, \sigma=.06$. The second version of uncertainty adjustment uses only the standard deviation of the cash flows themselves, in which case the mean is 
entered as zero and the standard deviation is entered as a whole number.

\section{Calculation of the Present Value}

In addition to the present value, which is automatically provided by the program, it is possible to specify more detailed output such as described by items 18 and 19.

18. DO YOU WANT THE MONTHLY CASH FLOWS PRINTED OUT?

This option allows the user to obtain cash flow figures by month for the whole portfolio for interest, principal, principal repayments and total cash flow.

19. DO YOU WANT DETAILED PREPAYMENTS, ETC?

An affirmative response for this option gives the user a detailed print out of cash flows by month for each individual loan in the portfolio. 
Sample Output

An example of the abbreviated program output appears as Table 8. The more detailed outputs are much longer and, therefore, examples have not been included. The output firsts lists the assumptions that have been used in the particular run called for. Since many of the data files are extensive, only the file names are referred to in the assumptions. The output then details each of the loans in the portfolin and prints the termination fractions that are assumed for the loan prepayments. The program then prints a present value and book value based on the initially specified term structure. The output then presents a second present value calculation, both of which are based on the revised or arbitrary term structure as specified. The percentage change in present value is calculated as the concluding data $i$ tem. 


\section{HESE CASH FLONS ASSUME:}

1. $0.00 \%$ LATF PAYMENTS

2- 100.00\% RECOVERY UF FGRECLUSURES

3- 0 MONTHS PREPAYMENT DEVALTY

4- TIE FOLLUNIIG FORECLUSUYE EXPERIENCE

$\begin{array}{llllllllll}0.0200 & 0.0200 & 0.0200 & 0.02110 & 0.0200 & 0.0200 & 0.0200 & 0.0200 & 0.0200 & 0.0200 \\ 0.0200 & 0.0200 & 0.0200 & 0.0200 & 0.0200 & 0.0200 & 0.0200 & 0.0200 & 0.0200 & 0.0200 \\ 0.0200 & 0.0200 & 0.0200 & 0.0200 & 0.0200 & 0.0200 & 0.0200 & 0.0200 & 0.0200 & 0.0200 \\ 0.0200 & 0.0200 & 0.0200 & 0.0200 & 0.0200 & 0.0200 & 0.0200 & 0.0200 & 0.0200 & 0.0200\end{array}$

5- PREPAYMENTS NERE TERM STRUCTURE UETERMINEO USING

FILE MORT.PST FOR PAST MORTGAGE NATES,

FII.E L.DT

FOR LIUUIDITY PREMIUMS,

APII) A SPHEAD OF 0.0210

6- IFKM STRUCTURE SPECIFIEN FROM FILE K.DT

7. SMIFTED TERA. STRUCTURE USING PATAMETERS

$R R=0.0150$ RR-HAT $=0.0150$ II $=0.0377$ II-HAT $=0.1477$

R- UICERTAINTY ALJUSTMENT ASSUMIIG

LHU $=0.500 \mathrm{MU}=0.000 \mathrm{~S} / \mathrm{GHA}=2000.000$

LOAN \# 1, AS UF 11 HAS a MaLANCE UF 1209\%. AT a HaTE OF .088

IT MAS 300 MONTHS LEFT, A UU HAS HEEN UN THF HUGKS O MOSTHS

WWI HAS THE FULLOWLVG PHEPAYMENT EXPEFIENICE

$\begin{array}{llllllllll}0.0124 & 0.0239 & 0.0344 & 0.0144 & 0.0544 & 0.0643 & 0.0137 & 0.0630 & 0.0923 & 0.1015 \\ 0.1177 & 0.1198 & 0.1288 & 0.1377 & 0.1465 & 0.1553 & 0.1640 & 0.1727 & 0.1814 & 0.1999 \\ 0.1045 & 0.2070 & 0.2155 & 0.2239 & 0.2323 & 0.2401 & 0.2490 & 0.2573 & 0.2056 & 0.2739\end{array}$

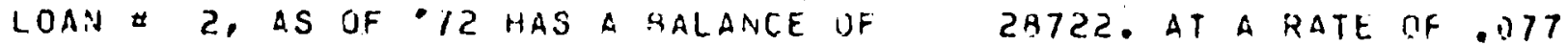

IT MIS 350 MONTHS LEFT, DNO HAS HEEN OR THE QUOKS O MONTHS

ANL HAS THE FULLOWING PREPAYMENT EXPEFIENCE

$\begin{array}{llllllllll}0.0127 & 0.0238 & 0.0342 & 0.0413 & 0.0344 & 0.0639 & 0.0734 & 0.0828 & 0.0920 & 0.1013 \\ 0.1104 & 0.1194 & 0.1254 & 0.1373 & 0.1461 & 0.1549 & 0.1636 & 0.1722 & 0.1808 & 0.1894 \\ 0.1974 & 0.2064 & 0.2149 & 0.2233 & 0.2317 & 0.2400 & 0.2463 & 0.2560 & 0.2049 & 0.2731\end{array}$

LDAN $\#$ 3. AS UF 73 HAS A SALANCE UF 26850 . AT A KATE UF .074

II TAS 360 MOIOHS LEFT, AYD HAS GEEN OA THE GUOKS O MONTHS

AN; HAS THE FILLONING PREPAYPENT TXPEPIENCE
$0.1177 \quad 0.0237 \quad 0.0342$
0.01940 .05120 .0638
0.0733
0.0827
0.0920
0.1013
0.1104
1.1283
0.1372
0.1400
0.1548
0.1635
0.1721
0.1207
0.1803
$0.19 .7 d$
0.2063
$\begin{array}{lllll}0.2147 & 0.2231 & 0.2315 & 0.2304\end{array}$
0.2482
0.2564
$0.2047 \quad 0.2729$

LDAN A H, AS OF TIL HAS A MALANCE OF

18273. AT A RATL UF .031

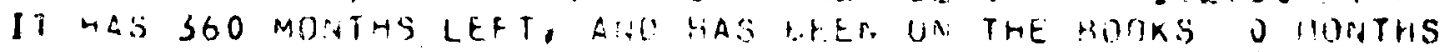

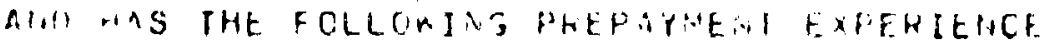

$0.01210 .0237 \quad 1.0343$

$0.11 .50 .1196 \quad 112450.1374 \quad 0.1402 \quad 0.1550$

$0.1 \% .10 .2060 \quad 0.21510 .22350 .03190 .2402$

0.11134

0.11824

0.19922

0.1014

0.1037

0.1724

10.1810

1). 1840

$0.24+50$

0.2051

0.2734 


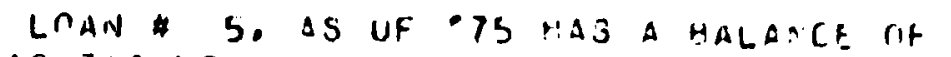

IT HAS 330 MONTHS LEFT. ANI) HAS HEEN UN THE 20806 . AT A RATE JF .094 AIVI) HAS THE FCLLO..IRG' PREPAY'IL IT EXPEKIEPICF

$\begin{array}{llllllllll}0.0127 & 0.0239 & 0.0343 & 0.0415 & 0.0544 & 0.0641 & 0.0757 & 0.0432 & 0.0925 & 0.1018 \\ 0.1109 & 0.1200 & 0.1290 & 0.1379 & 0.1467 & 0.1355 & 0.1545 & 0.1731 & 0.1816 & 0.1902 \\ 0.1988 & 0.2073 & 0.2158 & 0.22242 & 0.2327 & 0.2410 & 0.2494 & 0.2577 & 0.2600 & 0.2743\end{array}$

LDAN 6, AS UF - 76 HAS A BALANCE OF 3i368. AT A RATE UF .095 IT HAS 3BO MONTHS LEFT, ANO HAS BEEN ON THE HOCKS 9 MUNTHS AND. HAS THE FOLLOWING PREPAYAENT EXPERIEINCE

$\begin{array}{llllllllll}0.0128 & 0.0238 & 0.0343 & 0.0445 & 0.0544 & 0.0641 & 0.0738 & 0.0832 & 0.0925 & 0.1018 \\ 0.1194 & 0.1200 & 0.1290 & 0.1374 & 0.1467 & 0.1550 & 0.10143 & 0.1730 & 0.1816 & 0.1903 \\ 0.1488 & 1.2073 & 0.2158 & 0.2243 & 0.2327 & 0.2411 & 0.2444 & 0.2570 & 0.2001 & 0.2743\end{array}$

133730.570

GDOK VALUE $\triangle S$ UF $\cdot 76=$

122949.230

LOAN \# 1, AS OF 71 MAS A HALATCE UF

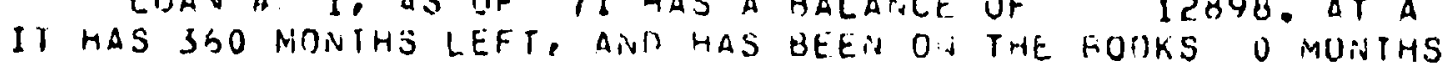

AND HAS THE FULLOHING PREPAYNEOIT FXPERIEUCE
1.0120
0.0239
0.0344
0.0414
0.05440 .0539
0.1377
0.1465
0.1553
0.0738
0.1640
0.0832
0.1727
0.0924
0.1814
0.1015
0.1995
$0.2070 \quad 0.2155$
0.2234
0.2323
$0.2407 \quad 0.2490$
0.2573
0.26360 .2730

LDAN 2 2, IS UF 72 HAS A BALANCE OF

II MAS 360 MONTHS LEFT, AINO HAS UEEN UNS THE BUOKS O MONTHS

Awr HIAS THE FOLL') ING PREPAYLLPT EXPERIENCE
0.0127
0.02380 .0342
0.11940 .123 .4
0.04 is
0.115410 .0640
0.1373
0.1401
0.1549
0.0735
0.0828
0.1630
0.1122
0.2483
0.2566
$\begin{array}{ll}0.0421 & 0.1013 \\ 0.12100 & 0.1694 \\ 0.2014 & 0.2731\end{array}$

LUAN \# 3, $\triangle S$ JF 73 HAS a GALANCE OF

26B50. AT A RATE UF, .074

IT HAS 3 CO NOVTHS LEFT, AMT HAS HEEN O: THE BUOKS I MONTHS

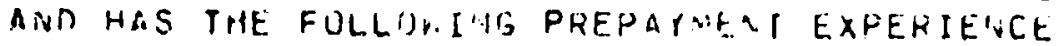

$\begin{array}{llllllllll}0.0127 & 0.0237 & 0.0312 & 0.0442 & 0.0543 & 0.0639 & 0.0134 & 0.0827 & 0.0920 & 0.1013 \\ 0.1104 & 0.1194 & 0.1283 & 0.1372 & 0.1450 & 0.1548 & 0.1035 & 0.1721 & 0.1807 & 0.1893 \\ 0.1974 & 0.2063 & 0.2147 & 0.2231 & 0.2315 & 0.2399 & 0.2482 & 0.2564 & 0.2047 & 0.2729\end{array}$

LI:AN $\Rightarrow$ 4, IS OF 74 HAS A JALANCE. IPF

II HAS 360 MONTHS LEFT, ANR HAS YEFR UP THE RUTKS O MONTHS

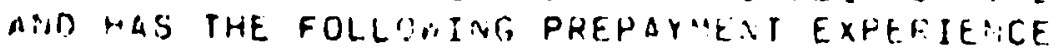

\begin{tabular}{|c|c|c|c|c|c|c|c|c|c|}
\hline & $\begin{array}{l}0.0237 \\
0.1196 \\
0.2066\end{array}$ & $\begin{array}{l}10.0341 \\
0.1245 \\
0.2151\end{array}$ & $\begin{array}{l}0.0445 \\
0.1374 \\
0.2255\end{array}$ & $\begin{array}{l}0.1543 \\
0.1442 \\
0.2319\end{array}$ & $\begin{array}{l}0.0640 \\
0.1550 \\
0.21402\end{array}$ & & $\begin{array}{l}0.0829 \\
0.1124 \\
0.256 .9\end{array}$ & $\begin{array}{l}0.0922 \\
0.1+110 \\
0.2651\end{array}$ & \\
\hline
\end{tabular}

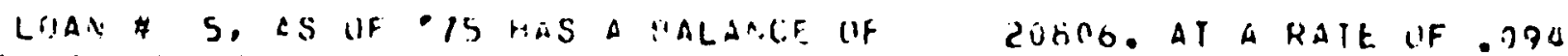

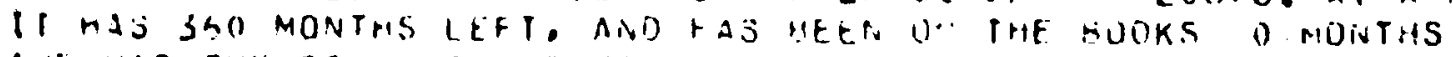

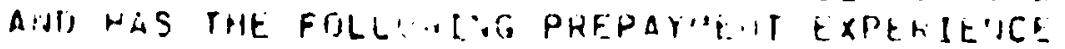

$0.0127 \quad 11.12570 .13440 .04400 .1514$ 1.

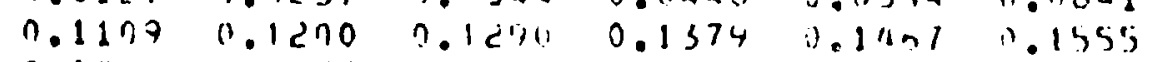

$0.14 m 811.2113011 .21540 .22420 .23270 .110$

$0.01370 .003 ?$

$0.1043 \quad 0.1730$

0.0925

0.1010 41

0.1810

0.1912

$0.200 \mathrm{~s}$

0.2713 
LOMAN \# b, AS UF 10 HAS A HALAHCE liF IT MAS 360 MONIHS LEFT, ARE HAS WEEN OU THE IUULSS G MONTHS AID HAS THE FOLLÓNING PREPAYMENT EXPERIE:C. E

$0.0127 \quad 0.02390 .031440 .0445 \quad 0.0544 \quad 0.0642$

$? .1109$

$0.1200 \quad 0.1290$

0.1379

0.0544

0.0642

$0.0754 \quad 0.0832$

0.1467

0.1043

0.1730

0.0925

0.1018

0.1988

0.2073

0.2156

0.2243

0.2327

0.24110 .2404

0.2578

$0.1816 \quad 0.19113$

0.20010 .2743

PHESEIVT VALIJE AS OF $10=$

132722.710

BOUK VALUE AS OF $76=$

122449.230

PERCEHT CHANGE IN PV $=-0.754$ 


\section{REFERENCES}

Curley, A. J. and Guttentag, J. M. 1974. "The Yield on Incured Residential Mortgages." Explorations in Economic Research, National Bureau of Economic Research, No. T (Sumer 1974), 114-61.

Hakansson, N. 1971. "Optional Entrepreneurial Decisions in a Completely Stochastic Environment." Management Science (March).

McCulloch, J. H. 1975. "An Estimate of the Liquidity Premium." Journal of Political Economy (January-February), 95-119.

Finance (June), $811-830$.

Morrison, J. 1977. "Interest Rate Risk in Commercial Banking: Some Implications for Capital Adequacy." Dissertation submitted to Graduate Division, University of California, Berkeley, June 1977.

Rubinstein, M. E. 1973. "Corporate Financial Policy in Segmented Securities Markets." Journal of Financial and Quantitative Analysis (December) 749-761.

1975. "The Valuation of Uncertain Income Streams and the Pricing of Options." Research Paper in Finance, working paper No. 37, Berkeley Institute of Business and Economic Research, University of California (August). 
APPENDIX A 


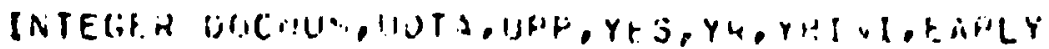

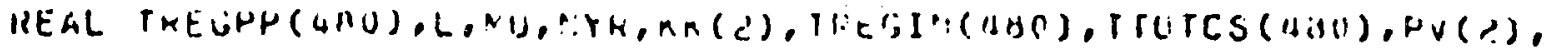

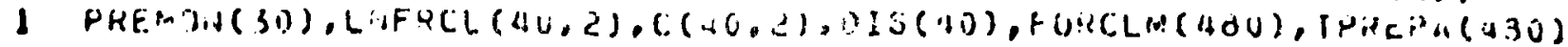

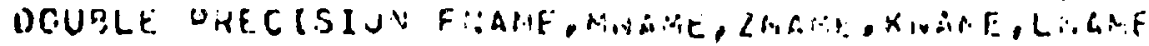

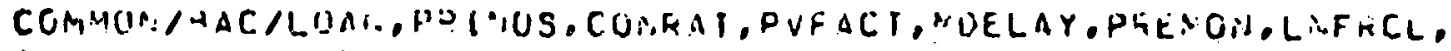
1 AF ICI,SFACT

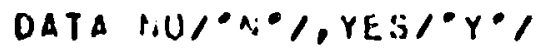

$I P C=1 \cdot N$

EARLY $=11900$

$001 \quad I=1.40$

$1 \quad$ OIS (I) $=0.0$

10

WRITE $(5,100)$

10)

FORMAT(" ENTER THE SAVINGS $x$ LUAT. EOChET P:O. AP:D THE H OF LUARS

READ $(5, *) D O C$ iss:i, UL

WRITE $(5,111)$

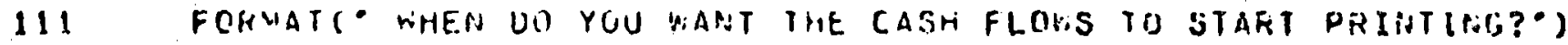

HEAD(S, +) YRINI

NRTTE('), 101)

101 FOKMATE IS THE LOAIN DATA UN: DISK?")

REAN $(5,102) A$ INS

10? FOR'WAT(Al)

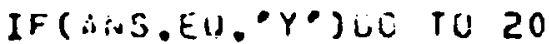

RIR TRE $(5,104)$

IOL FURAT( ".HAT :CULO YOU LIXE TO (ALL THE FILE?')

READ $(5,105) Z$ ZIAAVE

105 FOR:ALT(ALU)

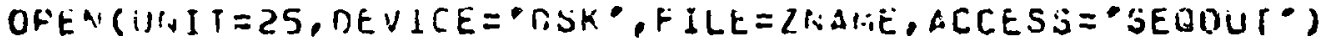

UO ?97 NACALL $=1$. II!

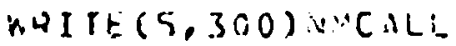

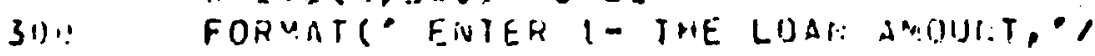

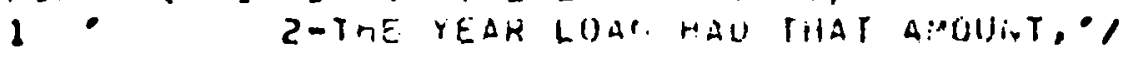

2 - 3-THE ronTHaCt Rate, 1

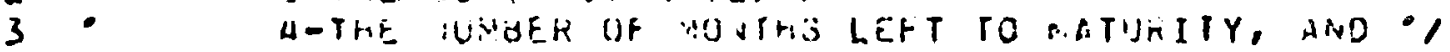

4 - 5-THE LGE (IA MUNIHS) UF LOAH \& $\because$ IZ)

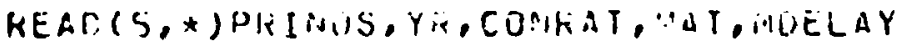

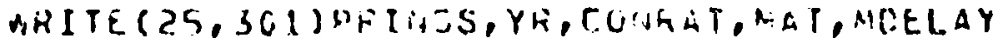

jUI FORNAT(F13,0,IS,FB, 4, ZIS)

IF (YR.LI, EARLY)EARLYEYR

CORITISUE

CLOSE (UVIT $=2.5)$

GO TO 30

2) WRITE $(5,116)$

Ine FCIRAT( .HAT FILE IS IT IIN?")

REAQ(S, (I) S) ZNA IE

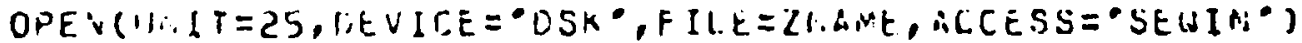

DQ $23 ! \quad l=1, N L$

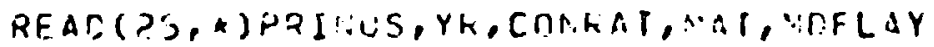

IF (YS.LT.EAFLY)FAYLY $=Y K$

C.'S CONTIIJUE

CLOSE (.1.1T $=25)$

S.j. WYITE $(5,107)$

lil

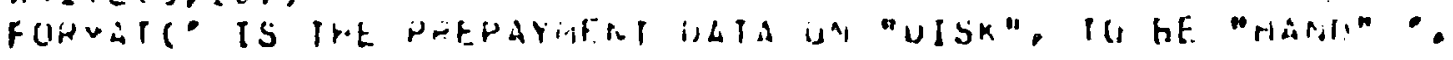

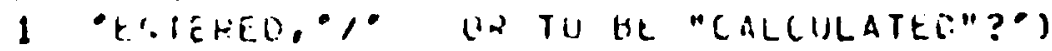

NEAD $(5,102) 16 . P$

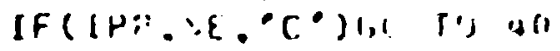

HRI It. $(5,1015)$

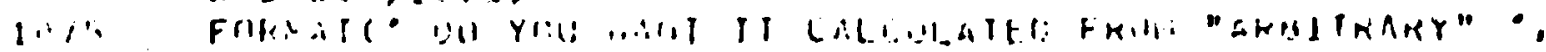


1 Prontgage bates, 10

5 - vithtrabe nates?")

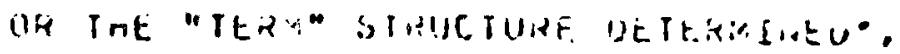

KEAN $(5,102)$ IPR.

IF ( IPC.NE.・A*)G TU S'S

WR ITE $(5,108)$

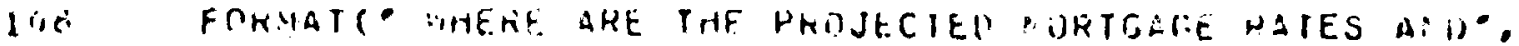

I DISCDUNI POI"TS?")

READ (5, 1U5) MiNAS:E

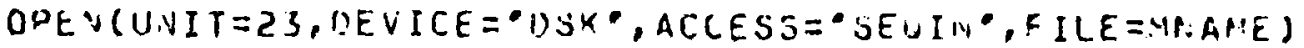

$N E A O(23, \star)(((C,(I, J), J=1,2)$, i I $3(1)), I=1,40)$

CLOSE (UNIT $=23)$

GO TU 70

SS ZWA $=$ YHINI-EARLY

IF (ZWN, LE. O.OO)G? TO 70

WRITE $(5,350) Z$ ZN!

350

FORNAT ( YUII :AEE

1 - POINTS. 1 "

READ $(5,105)$ MNAME

NNETEIFIX(ZHA)

OPEM(UNIT $=23$, OEVICE = OSK" "FILE= MUAAE, ACCESS=-SEOIM")

$\operatorname{REA} S(23, \star)(((C(1, J), J=1,2), D I S(1)), J=1, \cdots, \cdots)$

CLUSE (UNIT $=23)$

WIITE $(5,351)$

351 FOFUATC WHAT FILE ARE THE LIUUIOITY PREMIUNS LN?")

READ (5, 105)LiNADE

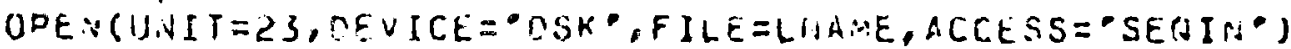

WR I TE $(5,352)$

352

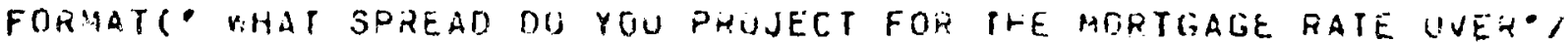

1 THE TREASUTYY GILL RATE? (I.E. 0.021) )

FIEAD $(5, *) S P R D$

GO TO 70

45 IF(IPD.NE. DO) TSU TU 50

W.RITE $(5,100)$

HEAD $(5,105)$ FHA AIE

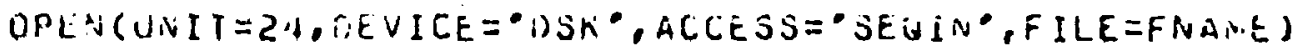

PPUUT $=N O$

UPP $=24$

31)

Gi) 1060

UPP $=5$

PiRI IE $(5,103)$

1.3 FOKWATC MOULO YOU LIKE TO HAVE THEM PUT OM DISK?")

RES S.D(5,102)PPOUT

IF (PFOUT, NE. $\cdot Y \cdot 160$ TO 60

WITIE $(5,104)$

HEAD $(5,105) F$ NANE

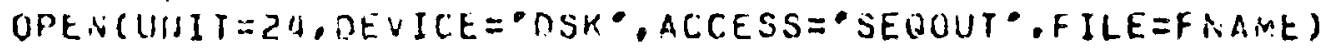

DU IF (IPD.PE. $\left.D^{\prime}\right)$ SRITE(S.61)

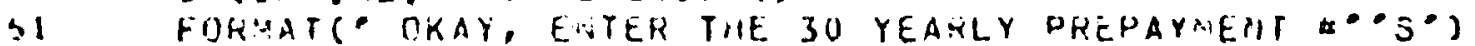

READ(UPP, *) (PPE $\because J i l(I), 1=1,30)$

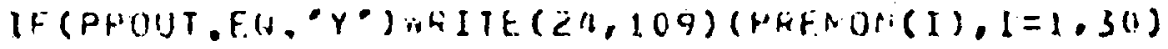

$174 \quad F(j K A A T(F 9.3)$

CLUSE (USIT $=2 L)$

II COUTISULE

$\therefore Q \perp T F(S .110)$

110 FOA

B.F $45(5,205)$ FNing

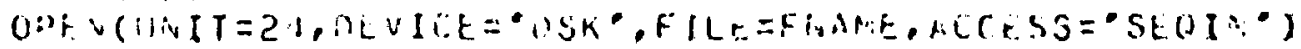

KE.A! $(3,4, *)((L \cdot+\cdots(1,1,1,1), J=1,2), L=1,10)$

Cl.1.j. $(1 .: 1)=? 4)$ 
: 9 (TE $(5,112)$

LEAD $(5, \pitchfork) P F O R$

112 FURYAT NQITE $(5,113)$

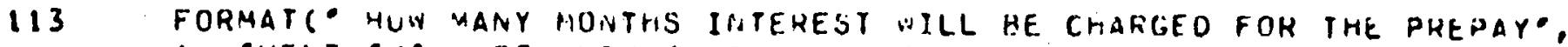

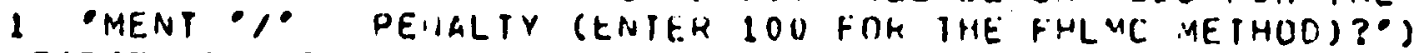

KEAD $(5, \star) \leadsto(I S P E N$

FORMAT( ' NTERE ARE THE $K^{\bullet \bullet S ~ F U U N U ? ") ~}$

REAO (5.105)KNAME

RRITE $(5,116)$

116 FORMAT(" DO YOU NANT TO ARUITRARILY SHIFT THE TERM STRUCTUAL?')

READ (5, 102) INTWK

IF(INTWK.'NE. PY') COO TO 71

WRITE $(5,106)$

KEAO $(5,105)$ FNAME

OPEN(UNI $T=20$, DEVICE $={ }^{\circ}$ OSK $, F I L E=F N A M E, A C C E S S={ }^{\circ}$ SEOIH')

60 TO 72

71 WQITE $(5,115)$

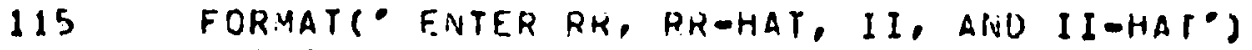

REAO $(5, *)$ QR, RQHAT, ZII, ZIIHAT

72 CONTINUE

$U=0$

VRITE $(3,117)$

117 FORMAT( OU YOU WISH TO AISUUST FUF UIVEERTAINTY?')

READ $(5,1 \cup 2) I F I, N$

IF (IFUN.NE. $Y \cdot)$ SOO TO 73

ARITE $(5,118)$

110 FORMAT6 ENTER 1- THE COKMELATION GETMEEN CASH FLONS ANI) "

1 - RETURH ON THE PIARKEI,, 0 2- THE NIEAN Uf (1+ THE?

2 GROWTA RATE UF TME CASH FLUAS), 1 " 3 - THE ",

3 -STANUARJ DEVIATIUN')

KEAD $(S, \star) R U, M U, S I G M A$

73 CONTINUE

ORITE $(5,119)$

119 FUHMAT( DO YLU MANT THE MORTHLY CASH FLOWS PEINTEU OUT?०)

READ $(5,102)$ OUT I

WRITE $(5,120)$

120 FORMAT( ${ }^{\circ}$ TO YIU HANT DETAILED PREPAYMENTS, ETC.?

READ (5,:П2)OUT2

URITE $(3,303)$ OUCHUM, PRLATE, PFUN, NOSPEN, (LNFRCL $(1,2), 1=1,40)$

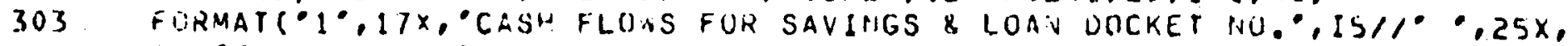

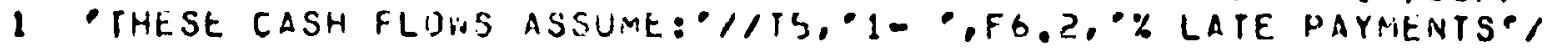

? TS, 2- $, F G, 2, \%$ RECOVEHY IIF PHECLUSURES*

3 T5, 3- - I0," MUINTHS PREPAYMENT DENALTY",

$4 T 5, \cdot 4-$ THE FOLLUNING FURECLUSIIRE EXPERIENCE'/

5 10FB.4/10F8.4/10FH. $+1 / 10 F 5.4)$

IF(IPP.NE. $\left.{ }^{\circ} C^{\circ}\right) G O$ TO $303 S$

IF (IPC.EO.*A*)GO TU 3033

OHITE (3,3032) MNANE, LIAME, SPHU

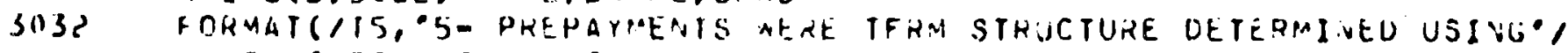

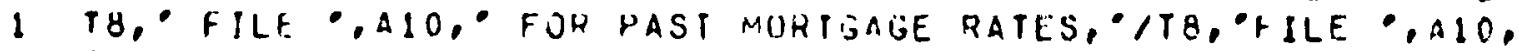

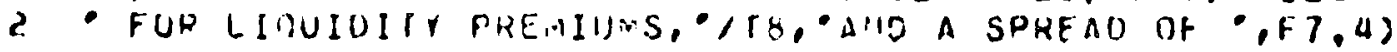

Gก TO 3041

3733 ORITE(3,3031) NIVAME

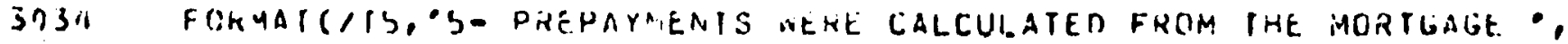


1 PHATES FOURU [A , AIOT)

GO TO 3041

30.55 VRITE $(3,304)$ HEEMUN

30 it

FORMATC/T5.:5- IHE FOLLOMING PHEPAYIAENT EXPERIENCE.'

1 IOFB.4, IOFH. 4. (UFd.4)

3041 WRITE 3,30112$) K N A M E$

3042 FORMAT(/15, 6- TERM STHIJCTUHE SPECIFIEU FHOM FILE $\because$ AIO)

IF (INTWK,EU. 'Y') ARITE $(3,3043) F A$ FIAE

3043 FORMAT $\left(/ 15,0^{\circ} 7\right.$ - SHIFTED TERA STRUCTURE FROM FILE • A10)

IF(INTAK. NE. "Y') WITE(3,3044)RF, RHHAT, ZII, ZIIHAT

3044 FORMAT(/T5,"7- SHIFTED TERA SIRUCTURE USING PARAMETERS,

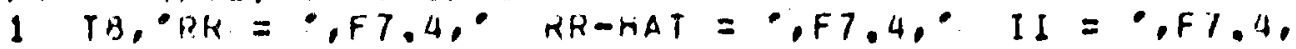

$2 \cdot I I-H A T=-, F 7.4)$

IF (IFUN. NE. "Y*) HRITE $(3,3045)$

3045 FORMAT(/T5, 8- NO UNCERTAINTY ADJUSTMENT')

IF (IFUA.EQ."Y०) MRITE $(3,3046)$ RD, MU, SIGMA

SO46 FIJRAATC/T5, B- UNCERTAINTY AUJUSTAENT ASSUMIAG $/$

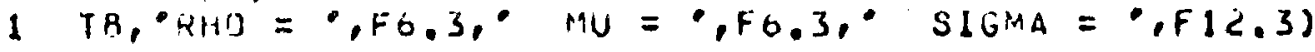

$P F U R=P F O R / 100$.

$00999 L L L=1,2$

BOKVAL $=0$

vo $5 \mathrm{~J}=1.480$

FORCLNi $(J)=0.0$

$110 \cos (J)=0.0$

TREG GU $(J)=0.0$

$\operatorname{TPRFPA}(J)=0.0$

TQLGPP $(J)=0.0$

3

CONTINUE.

IF (IPC.VE. P $\left.T^{\circ}\right) \mathrm{GO} 109$

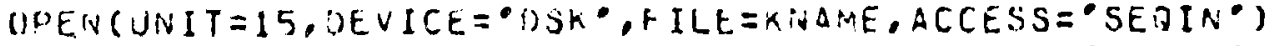

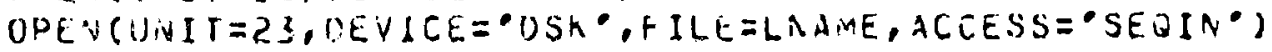

$I Z I=1$

INYR $=E A H L Y$

IF (ZN.U.LE.0.0)GO TO 6

$I Z I=I Z I+I F I \times(Z I N V)$

NYY $=Y A I N I$

6

$$
\mathrm{J}=0
$$

DO $7 \quad I=I \angle I, 40$

SUA $=0$

00 \& $J J=1,4$

$J=j+1$

$\operatorname{READ}(15, *) K K(2)$

IF( (LLL,EO.2), ANU. (INTWK,NE. 'Y•))CALL TVEE(HH,RRHAT,ZII, 1 ZIIHAT,Kk(Z),J)

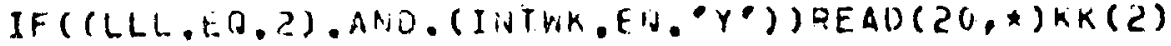

IF (J.EO, 1)RT $=h \times(C)$

IF(J.EQ.1)GU YO OS

CALL FORKAT (KK,J,B)

REAI) $(23, *) L$

65 $\quad S U M=S U H+i\}$

CALL SRTRAT $(R, L, R T)$

\& CORTINUF.

$C(i l l, 1)=N Y i$ :

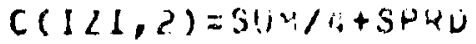




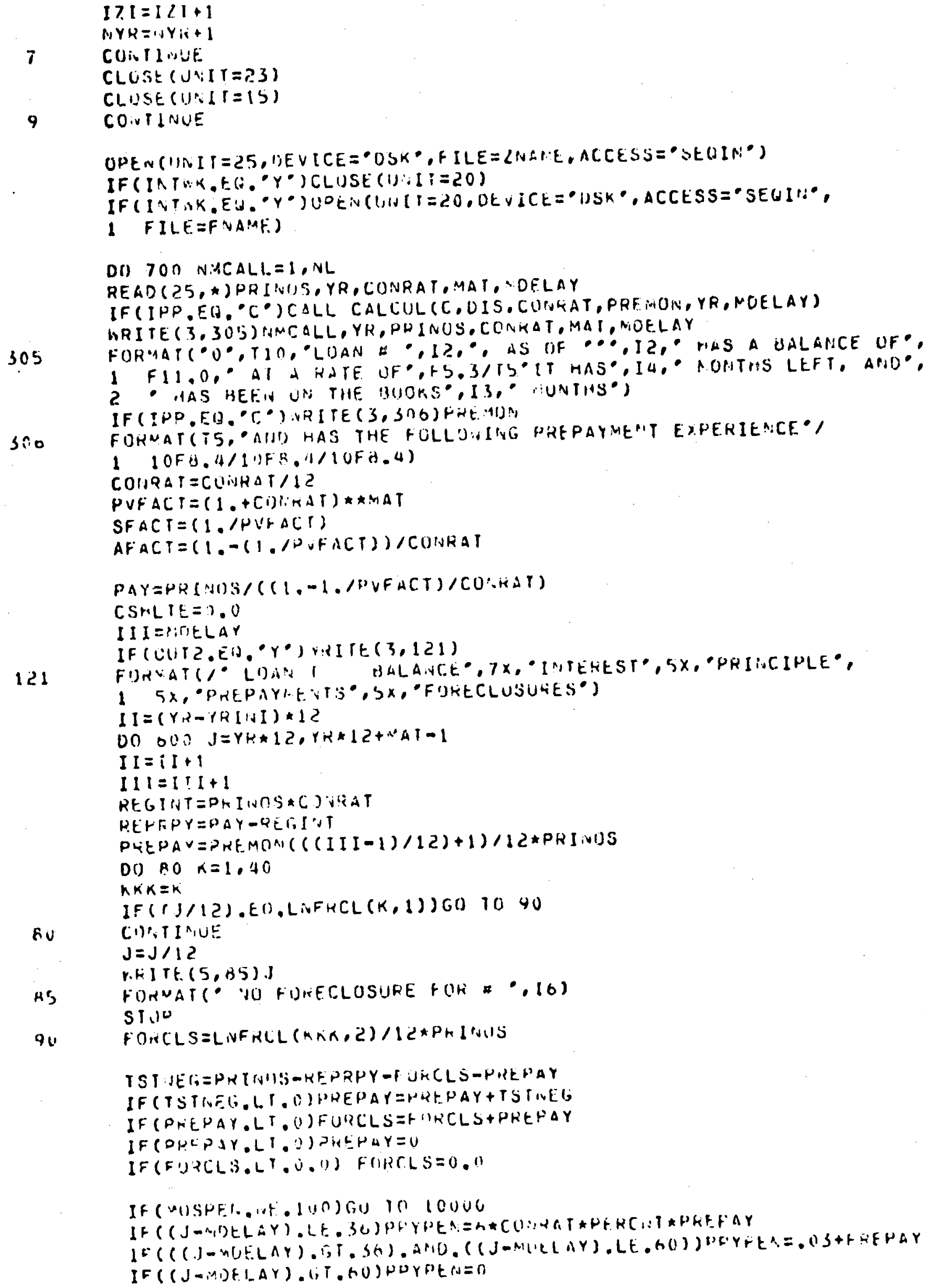


(;0 TU 10001

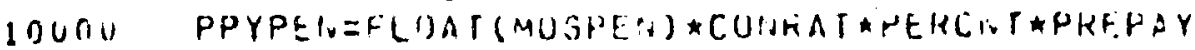

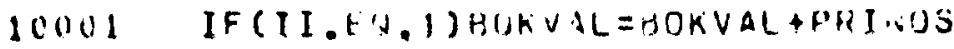

PRINOS =PKIINOS-KEPRHY-PREMAY FUPCLS

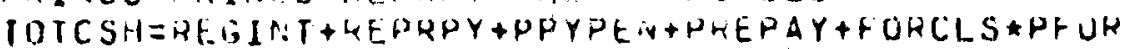

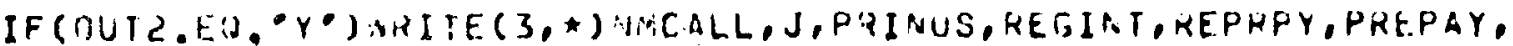
1 FUKCLS

$A F A C T=A F A C T-3 F A C T$

SFACT $=S F A C T /(1 . /(1,+C O N R A T))$

PAY $=P R I N U S / A F A C T$

IF (II.LE.O)GU TO 600

IF (II.GT.480)GU TO 600

TTOTCS(II) $=$ TTOTCS(II) + TUICSH

TPREPA (II) $=$ TPREPA (II) +PREPAY

FORCL.A(II) =FUNCLM(II) +FOKCLS

TREGI!I( II) $=$ TREGIN(II) + HEGINI

TREGPP(II) =TREGPP(II) +REPRPY

6DO) CONTINUE

700 COHTINUE

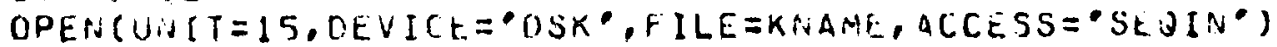

IF (IFUN, EY, "Y") OPEN (UNITEZS, VEVICF = OSK ,FILE =LVAME,

1 ACCESS $=\cdot S E Q I \cdot)$

$P \vee(L L L)=0$

$00.500 \quad[=3,480,3$

$\operatorname{REAO}(15, *)$ TK

$K K(2)=r x$

$J=(T-1) / 3+1$

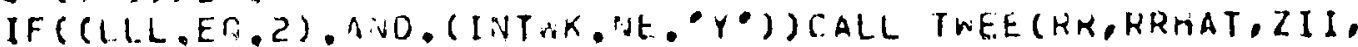

1 (IIHAT, TK,J)

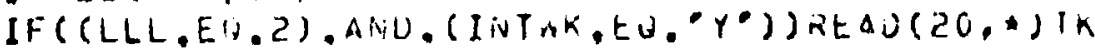

CALL DE AUU(TK,J, J)EOU)

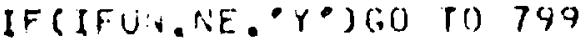

IF (J,FW, 1) HT $=K K(2)$

IF (J.E(U.1) GO TU 795

CALL FORRAT $(K K, J, A)$

READ $(23, \star) L$

CALL SHTRAT (R,L,RT)

795 CALL UHCT(TTUTCS(1), RO, MU,SIC,NA,RT,J,U)

$799 \quad P V(L L L)=P V(L L L)+(\operatorname{TTOTCS}(I-3)+\operatorname{TTOTCS}(I-1)+\operatorname{TTOTCS}(I)+U) / U E V$

$K K(1)=K K(2)$

BOR CONTINIJE

NRITE $(3,311) Y R I: 1, P V(L L L)$

ARITE $(3,313)$ YKINI, ,OKVAL

313

FOH HAT $(1 / T 24$, , DOOUK VALUF

CLOSE (UAIT $=25)$

CLOSE (UVIT $=15$ )

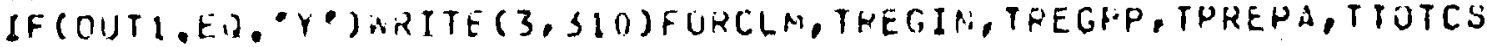

999 CONTITISE

PRCH $=((\operatorname{PV}(2)-P \vee(1)) / P \vee(1)) * 100$

NRITE $(3,3: 2)$ F ZL :

318

311

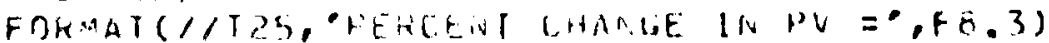

3111

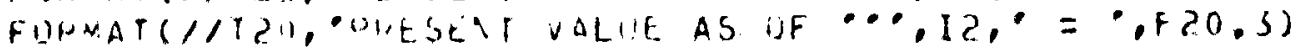

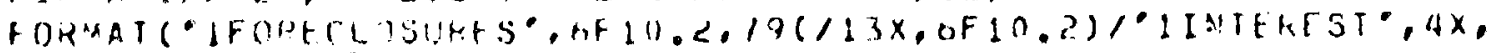

1 af $10.2,10(1 / 3 x$, of 10.2$) / 1$ PRISCIPAL $, 3 x, 3+10.2,79(115 x$, 


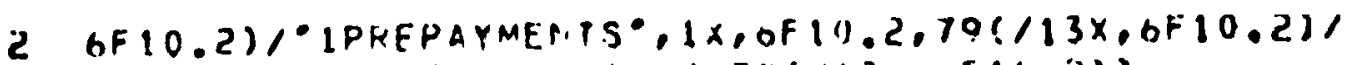

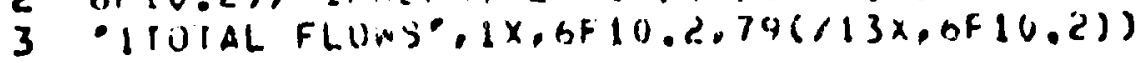

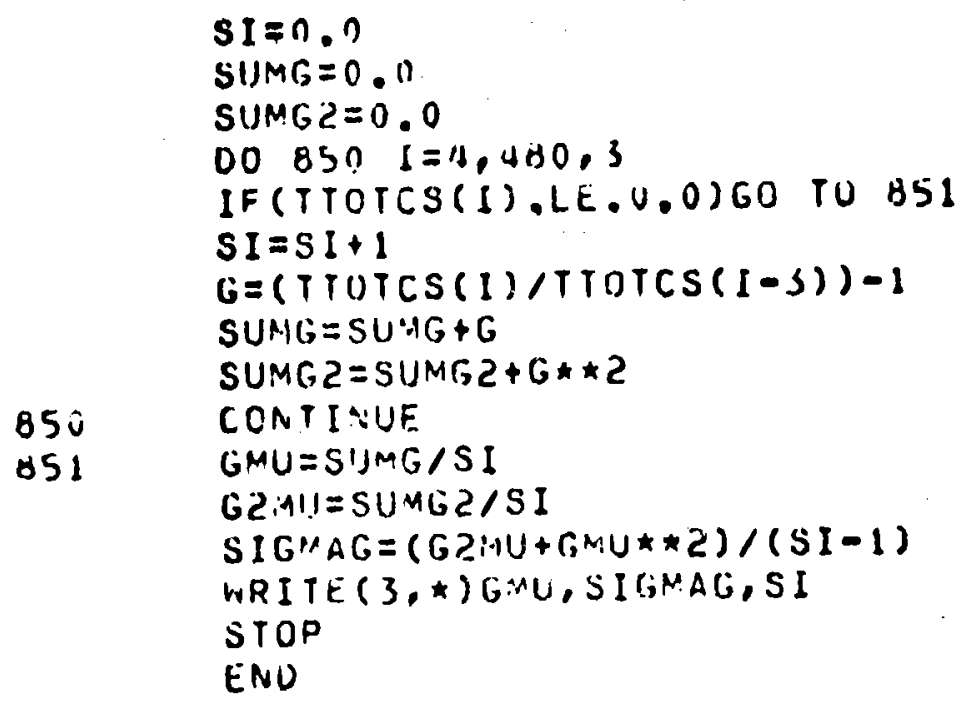


SUGRUUTIINE FURKAT $(K K, T, K)$

INTEGER T

REAL KK (2),K

$K=4 \star A L O S((E X P(K K(2) \star T / 4)) / E X P(K K(1) \star(T-1) / 4))$

RETURV

END

SUBROUTINE SPTRAT $(K, L, I)$

KEAL K,L,I

$I=K-L$

RETURN

END

SUBROUTINE THEE (RH, RRHAT, I I, I IHAT,KK, T)

INTEGER $T$

REAL II, IIHAT,KK

$K K=(1+K K) *((K K H A T-R R) /(1+K R)) \star E \times P(-.41-.14 * T * 3)$

$1+(1+K K) *((I I H A T-I I) /(1+I I)) \star E \times P(-.41-.09 * T * 3)$

$2+K K$

RETUR:

ENO

SIJHROUTINE UFCT(TTOTCS,HO, MU, SIGMA,RT,J,U)

REAL MU

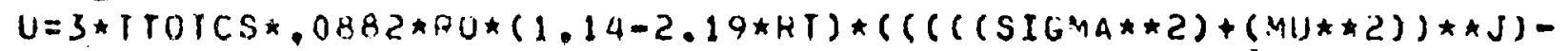
$1((M U * \star 2) \star \star J)) \star \star(.5))$

RETIIRN

ENO

SUBROUTINE UFCT(TTOTCS, RU, MU, SIGAA, RT, J,U)

REAL PU

$U=.08 F 2 * 20 *(1.14-2.19 * A T) * S 1 G .4 A$

RE IUITH

END 


\section{APPENDIX B}

LISTING OF DATA INPUT FILES 
The computer program allows the user to set up input files which contain data needed for performing the various calculations. The user simply references the file name at the appropriate place in the program, and all the data in the file is made available automatically. The forlowing pages contain examples of exact data with the name of each data file in capital letters preceeding the data. The nature of the data in each of the files has been discussed previously at the beginning of Section II. 


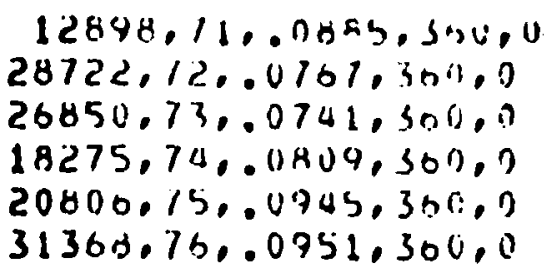

MORT.PST

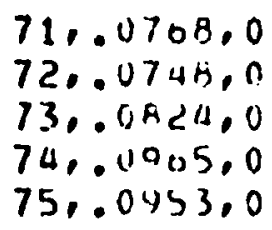

$$
\begin{aligned}
& 70, .02 \\
& 71.02 \\
& 72 . .02 \\
& 73 . .02 \\
& 74 . .02 \\
& 75 . .62 \\
& 76.02 \\
& 77 . .02 \\
& 78 . .02 \\
& 79 . .02 \\
& 80, .02 \\
& 81 . .02 \\
& 82 . .02 \\
& 83, .0 \text { ? } \\
& 80, .0 \text { ? } \\
& 85 . .02 \\
& 86.02 \\
& 87 . .02 \\
& 88 . .02 \\
& 89, .02 \\
& 90 . .02 \\
& 41 . .62 \\
& 92 . .02 \\
& 93 . .02 \\
& 911.0 \text { ? } \\
& 95, .02 \\
& 96 . .02 \\
& 97, .0 \text { ? } \\
& 98, .0 \text { ? } \\
& 99 . .02 \\
& 100, .02 \\
& 101 \ldots .02 \\
& 102, .02 \\
& 103, .02 \text {. } \\
& 104, .02 \\
& 105 . .02 \\
& 105 . .02 \\
& 10 \% \text {. } 0 \text { ? } \\
& 106.00 \mathrm{C} \\
& 109, .02 \\
& 110 . .02 \\
& 111 . .02 \\
& 11 \dot{11.02} \\
& 113, .11 \text { ? }
\end{aligned}
$$




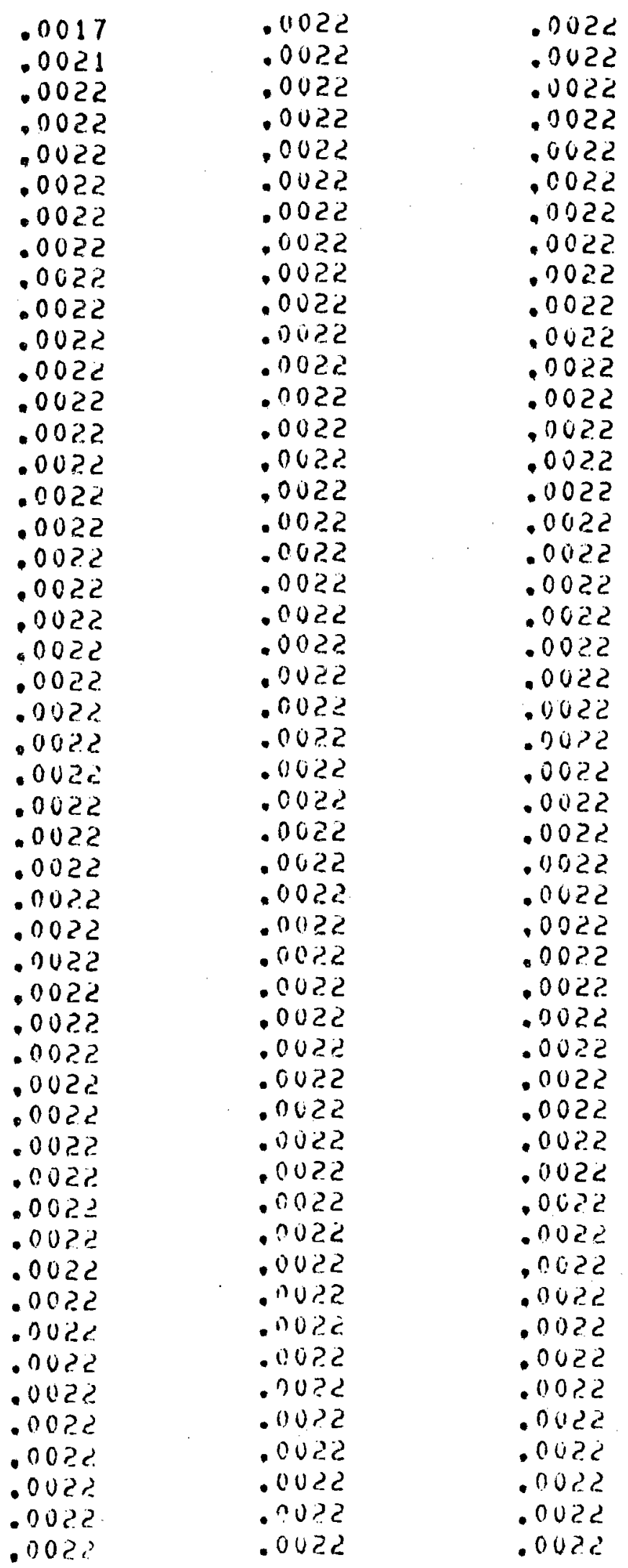




\section{K.DT.}

\begin{tabular}{|c|c|c|}
\hline 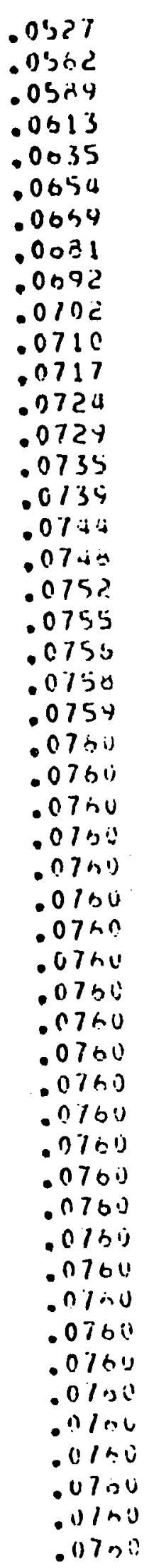 & $\begin{array}{l}.0760 \\
.0760 \\
.0760 \\
.0760 \\
.0760 \\
.0760 \\
.0760 \\
.0760 \\
.0760 \\
.0760 \\
.0760 \\
.0760 \\
.0760 \\
.0760 \\
.0760 \\
.0760 \\
.0760 \\
.0760 \\
.0760 \\
.0760 \\
.0750 \\
.0760 \\
.0760 \\
.0760 \\
.0760 \\
.0760 \\
.0760 \\
.0760 \\
.0750 \\
.0700 \\
.0700 \\
.0700 \\
.0760 \\
.070\end{array}$ & $\begin{array}{l}.0760 \\
.0760 \\
.0760 \\
.0760 \\
.0700 \\
.0760 \\
.0760 \\
.1760 \\
.0760 \\
.0760 \\
.0760 \\
.0760 \\
.0700 \\
.0760 \\
.0160 \\
.0760 \\
.0760 \\
.0760 \\
.0760 \\
.0750 \\
.0750 \\
.0700 \\
.0760 \\
.0700 \\
.0760 \\
.0700 \\
.0760 \\
.1760 \\
.0760 \\
.0760 \\
.0760 \\
.0760 \\
.0760 \\
.0760 \\
.0760 \\
.0760 \\
.0760 \\
.070\end{array}$ \\
\hline
\end{tabular}


AK.DT .

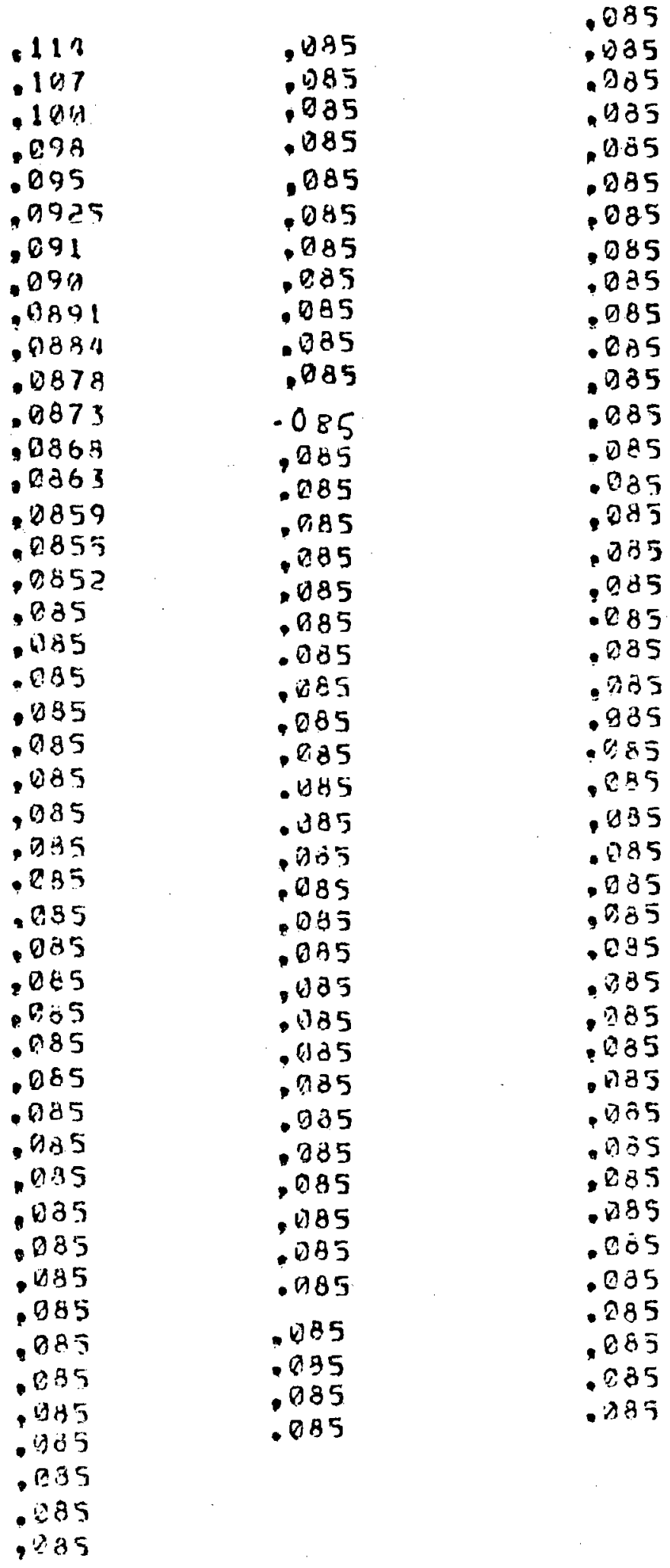

